\title{
Phosphate treatments for stone conservation: 3-year field study in the Royal Palace of Versailles (France)
}

\author{
Enrico Sassoni 1 • Clément Delhomme • Sébastien Forst • Gabriela Graziani (10) \\ Jérémy Hénin • Giulia Masi (D) Azzurra Palazzo • Olivier Rolland • \\ Veronique Vergès-Belmin
}

Received: 15 February 2021 / Accepted: 2 May 2021/Published online: 28 June 2021

(C) The Author(s) 2021

\begin{abstract}
Phosphate treatments for conservation of stone have provided so far encouraging results in laboratory studies, as they exhibit good effectiveness, compatibility and durability to accelerated weathering tests. However, limited data are available about their long-term performance in real environment. Here, a systematic evaluation of phosphate consolidants after prolonged exposure in the field is reported for the first time. Naturally weathered marble specimens and a XVII century marble sculpture located in the Park of the Royal Palace in Versailles were treated by various
\end{abstract}

Supplementary Information The online version contains supplementary material available at https://doi.org/10.1617/ s11527-021-01717-7.

E. Sassoni $(\bowtie) \cdot$ G. Graziani · G. Masi

Department of Civil, Chemical, Environmental and

Materials Engineering (DICAM), University of Bologna,

Via Terracini 28, 40131 Bologna, Italy

e-mail: enrico.sassoni2@unibo.it

C. Delhomme · A. Palazzo - O. Rolland

Free-lance conservator for the Château de Versailles,

Versailles, France

S. Forst

Atelier de restauration des Sculptures de Versailles, Château de Versailles, R.P.834, 78008 Versailles Cedex 1, France

\section{J. Hénin · V. Vergès-Belmin}

Laboratoire de recherche des monuments historiques (LRMH), 29, rue de Paris, 77420 Champs-sur-Marne, France formulations of the phosphate consolidant. Their conservation state was assessed before treatment by non-destructive methods (ultrasounds, color measurement, water absorption) and, in the case of the specimens, also by slightly destructive tests (SEM, FT-IR, MIP, IC). The conservation state of the specimens and the sculpture was further assessed right after treatment and then periodically monitored during exposure in the Versailles Park. Characterization after field exposure demonstrated that some formulations of the phosphate treatment are able to slow down marble deterioration, although it was not completely inhibited. Limited alterations in water absorption and aesthetic appearance confirmed the general compatibility of the phosphate treatment.

Keywords Marble Ammonium phosphate . Calcium phosphates $\cdot$ Hydroxyapatite $\cdot$ Ammonium oxalate $\cdot$ Durability

\section{Introduction}

Phosphate treatments for stone conservation are based on the idea of reacting the stone (containing $\mathrm{Ca}^{2+}$ ions) with an ammonium phosphate solution (containing $\mathrm{PO}_{4}{ }^{3-}$ ions), with the aim of forming new calcium phosphates $(\mathrm{CaP})$ inside pores and cracks and over the stone surface, with consolidating and protective function [1, 2]. Ideally, the reaction product is 
hydroxyapatite ( $\left.\mathrm{HAP}, \mathrm{Ca}_{10}\left(\mathrm{PO}_{6}\right)_{4}(\mathrm{OH})_{2}\right)$, which is the least soluble $\mathrm{CaP}$ at $\mathrm{pH}>4[1,3]$. Since their introduction in 2011 [1,2, 4, 5], phosphate treatments have received considerable attention, given their high potential in terms of:

- Effectiveness Phosphate treatments provide increases in mechanical properties fully comparable and often superior to commercial consolidants, such as nanolimes [6-9], nanosilica [9], ethyl silicate [10-14] and ammonium oxalate [13, 15-17], with the advantage of being effective after only $24-48 \mathrm{~h}$, whereas curing for at least 1 month is necessary for nanolimes and ethyl silicate [18, 19]. Notably, significant consolidation has been proven not only on carbonate substrates, but also on silicate ones (e.g. sandstones [14, 20] and cement mortars [6]), thanks to the addition of $\mathrm{Ca}^{2+}$ ions necessary to form the new $\mathrm{CaP}$ directly into the phosphate solution [21]. Moreover, phosphate treatments have also demonstrated a good protective efficacy, as they delay marble dissolution in acidic solutions [22, 23].

- Compatibility Phosphate treatments generally cause modest color changes [3] and alterations in open porosity, pore size distribution and water transport properties of the substrate [1, 3, 10]. Possible issues arising with treatments that make the treated substrate temporarily hydrophobic (e.g. ethyl silicate) are hence avoided [10, 11, 19, 20].

- Durability Results obtained so far suggest that phosphate treatments are able to increase the stone resistance to cycles of heating-cooling [13], bowing [13], wetting-drying [1, 11], freezing-thawing [11] and salt crystallization [8, 11, 24]. The susceptibility of phosphate treated-stone to biodeterioration, possibly favored by unreacted ammonium phosphate remaining in the stone, has also been specifically investigated [25] and several routes to prevent biodeterioration have been highlighted [3].

With the aim of testing the phosphate treatments in conditions as close as possible to those of real artworks in the field, many laboratory studies have involved artificially weathered samples $[1,10,15,26-28]$ and/ or accelerated ageing of the treated specimens $[8,11,13,24,25]$. Although very important to increase the reliability of laboratory studies [29], such attempts can hardly be fully representative of the complex conditions experienced in the field, where both the substrate conditions [30-32] and the environmental conditions [33-35] play a very important role. To account for the complexity of real situations, a few studies have assessed the performance of the phosphate treatments in the field [9, 25, 36, 37]. Various cases of successful application onto real artworks in Italy, Cyprus, Turkey and the Vatican City have been reported [25], but only in a few cases detailed scientific data were made available $[9,36,37]$.

In the present paper, we report the results of the first long-term study aimed at systematically evaluating the performance of the phosphate treatment after prolonged exposure in the field. In particular, the objective of the present study was twofold, as illustrated in Fig. 1. First, the field performance of 5 different formulations of the phosphate treatment was evaluated on naturally weathered marble specimens, in comparison with 2 alternative treatments and an untreated reference, for a total of 8 conditions. Untreated and treated specimens were exposed in the Park of the Royal Palace in Versailles for 3 years and periodically monitored. Second, the field performance of one formulation of the phosphate treatment was evaluated on a XVII century marble sculpture, affected by grain loss. The sculpture, permanently exposed outdoors in the Versailles Park, was characterized before treatment and then monitored after treatment, to evaluate the treatment performance in the long term.

\section{Materials and methods}

\subsection{Field testing of the marble specimens}

\subsubsection{Specimens}

A naturally weathered marble slab, which had been stored in the "Atelier de restauration des sculptures de Versailles" (Laboratory of Conservation of Versailles Sculptures), was sawn into $10 \times 10 \times 3 \mathrm{~cm}^{3}$ prismatic specimens. The slab exhibited a pale yellowish patina on one side and some biological growth on the other side. To avoid possible interferences between the treatments and bio-organisms, the consolidants were applied onto the specimen face exhibiting the yellowish patina and no obvious biological growth. For each treatment condition, 2 replicates were used. 


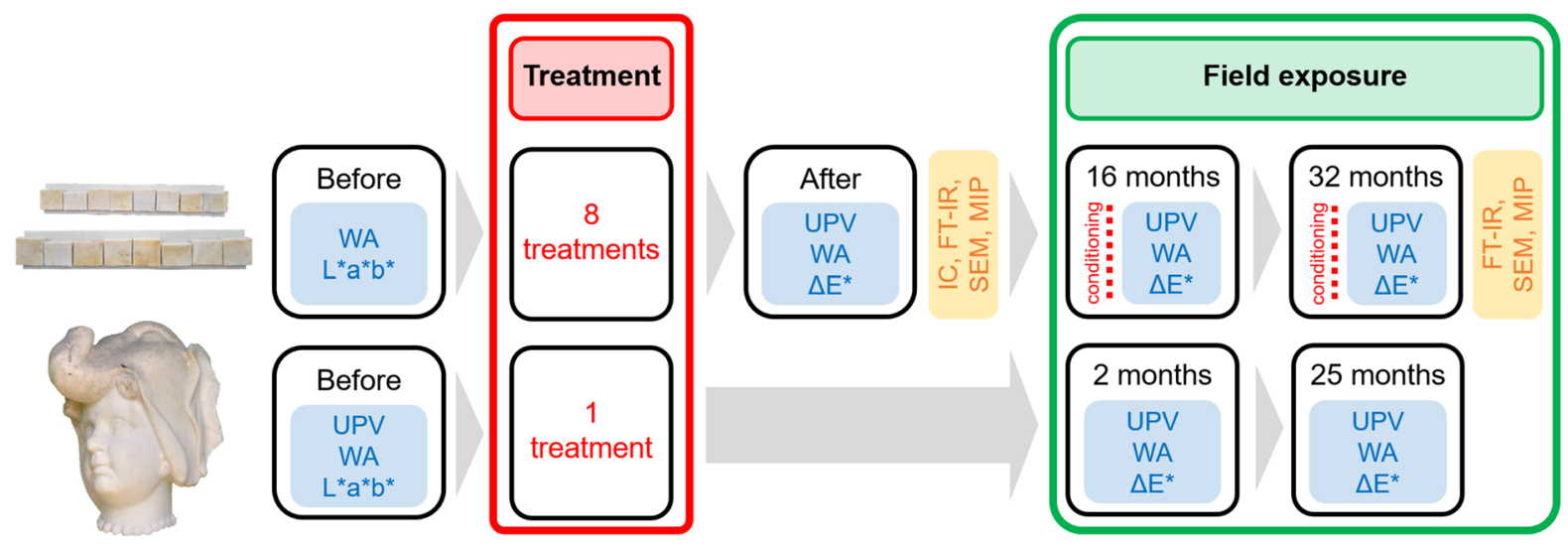

Fig. 1 Scheme illustrating the rational of the study, with indication of the timing of the characterization tests performed on the marble specimens and the marble sculpture, before and after treatment

\subsubsection{Treatments}

Diammonium hydrogen phosphate (DAP, $\left(\mathrm{NH}_{4}\right)_{2-}$ $\left.\mathrm{HPO}_{4}\right)$, calcium chloride dihydrate $\left(\mathrm{CaCl}_{2} \cdot 2 \mathrm{H}_{2} \mathrm{O}\right)$, aluminum nitrate nonahydrate $\left(\mathrm{Al}\left(\mathrm{NO}_{3}\right)_{3} \cdot 9 \mathrm{H}_{2} \mathrm{O}\right)$, ammonium oxalate $\left(\left(\mathrm{NH}_{4}\right)_{2} \mathrm{C}_{2} \mathrm{O}_{4}\right)$, ethanol $(\mathrm{EtOH})$ and isopropanol (IPA), all purchased from SigmaAldrich (assay $>99 \%$ ), were used.

In total, 8 treatment conditions were considered, as detailed in the following:

(1) Untreated reference ("UT").

(2) Aqueous solution containing 1 M DAP ("1 M"). This formulation was the first one proposed in $2011[1,2]$ and was here tested mostly as a reference.

(3) Aqueous solution containing $1 \mathrm{MDAP}+1 \mathrm{mM}$ $\mathrm{CaCl}_{2}$ (" $\mathrm{CaCl}_{2}$ "). This formulation involves addition of $\mathrm{CaCl}_{2}$, with the aim of favoring $\mathrm{CaP}$ formation [21] and preventing even minimal $\mathrm{Ca}^{2+}$ release from the substrate [21]. In previous studies, this formulation showed a good balance of consolidating and protective abilities [13, 16, 21, 22].

(4) Hydroalcoholic solution containing $0.1 \mathrm{M}$ $\mathrm{DAP}+0.1 \mathrm{mMCaCl}+10$ vol\% $\mathrm{EtOH}$ ("EtOH”). This formulation involves addition of ethanol, with the threefold aim of reducing the DAP concentration (because ethanol allows for $\mathrm{CaP}$ formation even at low DAP concentration), reducing the tendency of the new $\mathrm{CaP}$ layer to crack during drying [16] and reducing the porosity of the newly formed $\mathrm{CaP}[38]$.
(5) Hydroalcoholic solution containing $0.1 \mathrm{M}$ DAP $+0.1 \mathrm{mMCaCl}+10$ vol\% IPA (labelled "IPA"). This formulation is similar to the previous one, but involves addition of isopropanol instead of ethanol, as IPA is expected to be even more effective than ethanol [16].

(6) Aqueous solution containing 3 M DAP, followed by application of a limewater poultice (" $3 \mathrm{M}$ ”). This formulation involves a very high DAP concentration, with the aim of increasing the amount of $\mathrm{PO}_{4}{ }^{3-}$ ions available to form HAP. The second step (i.e. application of a limewater poultice after the DAP-treatment) is aimed at favoring further $\mathrm{CaP}$ formation (by supplying additional $\mathrm{Ca}^{2+}$ ions) and removing unreacted DAP from the stone pores (by transport into the poultice during drying) [39]. To this latter aim, it is important to let the treated substrate dry after DAP application and before limewater poultice application [39]. Previous studies showed that this formulation is able to consolidate even strongly decayed substrates $[13,15,27,39]$, even though the protective ability is limited [23].

(7) Hydroalcoholic solution containing $0.1 \mathrm{M}$ $\mathrm{DAP}+0.1 \mathrm{mM} \mathrm{Al}\left(\mathrm{NO}_{3}\right)_{3} \cdot 9 \mathrm{H}_{2} \mathrm{O}+10$ vol\% $\mathrm{EtOH}$ ("AlP"). This formulation is aimed at forming aluminum phosphates (AlP, ideally $\mathrm{AlPO}_{4}$ ) instead of CaP, because, theoretically, $\mathrm{AlPO}_{4}$ has a better match with calcite in terms of lattice parameters, compared to HAP [40].

(8) Aqueous solution containing 5 wt\% ammonium oxalate (labelled "AmOx"). This treatment was 
first proposed by Matteini in the ' $90 \mathrm{~s}$, with the aim of forming a passivating layer of calcium oxalate monohydrate (whewellite) over the surface of carbonate stones, so as to increase their resistance to dissolution in acid rain [41]. The treatment has also provided encouraging results as a stone consolidant, reportedly being able to increase the cohesion of weathered marble down to a depth of $5 \mathrm{~cm}$ from the treated surface [41]. Considering that the AmOx treatment is frequently used in the practice of stone conservation [30-32], in the present study it was considered as a benchmark.

\subsubsection{Application method}

All the treatments were applied by poulticing. Cellulose pulp (BW40, short fibers) was mixed with the various solutions in a 1:4 weight ratio. A $10 \mathrm{~mm}$-thick layer of poultice was applied onto the $10 \times 10 \mathrm{~cm}^{2}$ specimen face exhibiting the yellowish patina. After poultice application, the specimens were covered for $24 \mathrm{~h}$ with a plastic film to prevent evaporation, then the poultice was removed, the specimens rinsed with water and left to dry in room conditions.

In the case of the " $3 \mathrm{M}$ " treatment, after drying for 3 days the specimens were subjected to the application of a limewater poultice ( $1: 4$ weight ratio of dry pulp to limewater). The poultice, covered with a plastic film, was left for $24 \mathrm{~h}$, then the plastic film was removed and the poultice was left to dry in contact with the samples for about 3 days. The specimens were finally rinsed with water and dried at room temperature.

\subsubsection{Characterization}

The specimens were characterized by (Fig. 1): (i) nondestructive tests, periodically repeated throughout field exposure; (ii) destructive tests, performed on samples obtained by wet sawing a thin slice $\left(0.5 \times 3 \times 10 \mathrm{~cm}^{3}\right)$ from the specimens right after treatment and then again after field exposure for 32 months.

- Ultrasonic pulse velocity (UPV). The consolidating effectiveness was evaluated by measuring the UPV, which in marble is strongly correlated with open porosity, compressive and tensile strength [42]. The measurement was performed in direct transmission mode across the $3 \mathrm{~cm}$ thickness, using a portable instrument (AU2000 Ginger CEBTP with $60 \mathrm{kHz}$ transducers) and a rubber sheet between the transducers and the specimens.

- Water absorption (WA). The change in water absorption was determined using the sponge method, which allows to measure the amount of water absorbed by a substrate by weighing the wet sponge before and after contact with the substrate for a given time [43].

- Color change $\left(\Delta E^{*}\right)$. The color change $\Delta E^{*}$ was determined by measuring the CIELab color parameters $\left(L^{*}=\right.$ black-white, $a^{*}=$ green-red, $b^{*}=$ blue-yellow) before and after treatment, using a portable instrument (Chroma Meter CR-410), and then calculating the color change as $\Delta E^{*}=$ $\left(\Delta L^{*^{2}}+\Delta a^{*^{2}}+\Delta b^{* 2}\right)^{1 / 2}$.

- Fourier transform infrared spectroscopy (FT-IR). FT-IR analysis was carried using a Spectrum Two Perkin Elmer Spectrometer (ATR mode, 16 scans, range $4000-400 \mathrm{~cm}^{-1}$, step size $1 \mathrm{~cm}^{-1}$, resolution $1 \mathrm{~cm}^{-1}$ ) on powder samples obtained by scratching with a spatula from the treated surface of the slices cut from each specimen.

- Scanning electron microscopy (SEM). The morphology of untreated and treated samples, obtained by chisel from the slices, was observed using a FEG-SEM Tescan Mira3. Before observation, the samples were made conductive by sputtering with aluminium.

- Mercury intrusion porosimetry (MIP). The pore size distribution was determined by MIP, using a Pascal 140 and 240 instrument, on samples $\left(\sim 1 \mathrm{~cm}^{3}\right)$ obtained by chisel from the slices. MIP samples always included the originally treated surface, as the most pronounced alterations in pore size distribution were expected to occur near the surface.

- Ion chromatography (IC). IC was used to determine the presence of hygroscopic salts and free chlorides (possibly deriving from the use of $\mathrm{CaCl}_{2}$ ). Soluble fractions were extracted from powdered samples by boiling in distilled water, then the obtained solutions were analysed with a Dionex ICS 1000 instrument. 


\subsubsection{Field exposure}

After treatment, the specimens were exposed in the Versailles Park (Fig. 2) at $2 \mathrm{~m}$ height, over plastic holders with $45^{\circ}$ inclination with respect to the horizontal to allow for rain runoff, with the treated face exposed towards south/south-east.

After 16 and 32 months since the treatment (Fig. 1), the non-destructive tests were repeated, while destructive tests were repeated only after 32 months. It is worthy to note that, whereas measurements before and right after consolidation were taken after simply allowing the specimens to equilibrate in room conditions, measurements after 16 and 32 months were taken after pre-conditioning the specimens in a ventilated oven at $65^{\circ} \mathrm{C}$ for $48 \mathrm{~h}$, to remove moisture from the pores. After pre-conditioning, the specimens were let equilibrate in constant conditions $\left(T=21^{\circ} \mathrm{C}\right.$, $\mathrm{RH}=50 \%$ ) for 1 week before testing.

The environmental aggressiveness during the 32 months of field exposure (started in May 2017) was evaluated by analyzing environmental data made freely available by Météo-France. In particular, to estimate the number of freezing-thawing cycles, the daily values of air temperature, relative humidity and rainfall, measured by the closest survey station (located in Orly, about $25 \mathrm{~km}$ from the Royal Palace), were analyzed. According to a previously proposed methodology [34], freezing was assumed to occur on those days when air temperature dropped below $0{ }^{\circ} \mathrm{C}$ and water was present in the stone, because on the same day either rainfall occurred or relative humidity was higher than $80 \%$, so that condensation on the stone surface likely took place. Of course, such assumptions only allow for a rough estimation of the actual freezing of water inside the marble pores and fissures (because environmental data measured close to stone surface would be needed and because the actual freezing temperature inside the stone depends on the pore size [34]), but still useful indications on the likelihood of frost-related risk can be derived.

\subsection{Field testing of the marble sculpture}

\subsubsection{Sculpture}

The selected sculpture was a free standing Carrara marble bust from the late XVII century, called "L'Afrique" (The Africa), as suggested by the elephant-shaped hat on the woman's head (Fig. 3). The sculpture is located in the park of the Grand Trianon, in particular in the Amphitheater. The bust is placed in a recess within a hedge, hence partially sheltered from direct exposure to sun, rain and wind.

In May 2017, the bust exhibited granular disaggregation, especially in small carved parts, such as the nose, the breast and the elephant nose (Fig. 3). Before treatment, particulate matter accumulated onto the sculpture was dusted off and the marble surface was gently rinsed with water. The sculpture was left to dry for a few hours before the treatment application.

\subsubsection{Treatment}

The bust was treated with the " $\mathrm{CaCl}_{2}$ " formulation, considering that previous studies showed its ability to provide a good balance of consolidating and protective ability [13, 16, 21, 22], together with an increase in marble resistance to thermal weathering [13].

To prepare the phosphate solution, the same chemicals described in Sect. 2.1.3 were used.
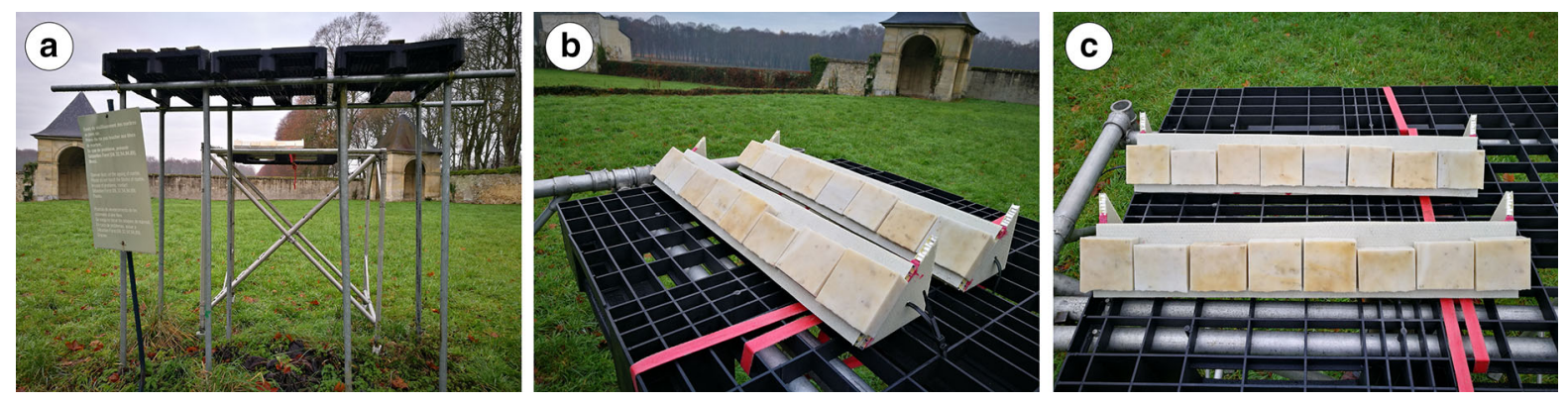

Fig. 2 Specimen exposure in the Park of the Versailles Palace: a height from the ground; $\mathbf{b} 45^{\circ}$ inclination with respect to the horizontal; c distancing among the specimens 

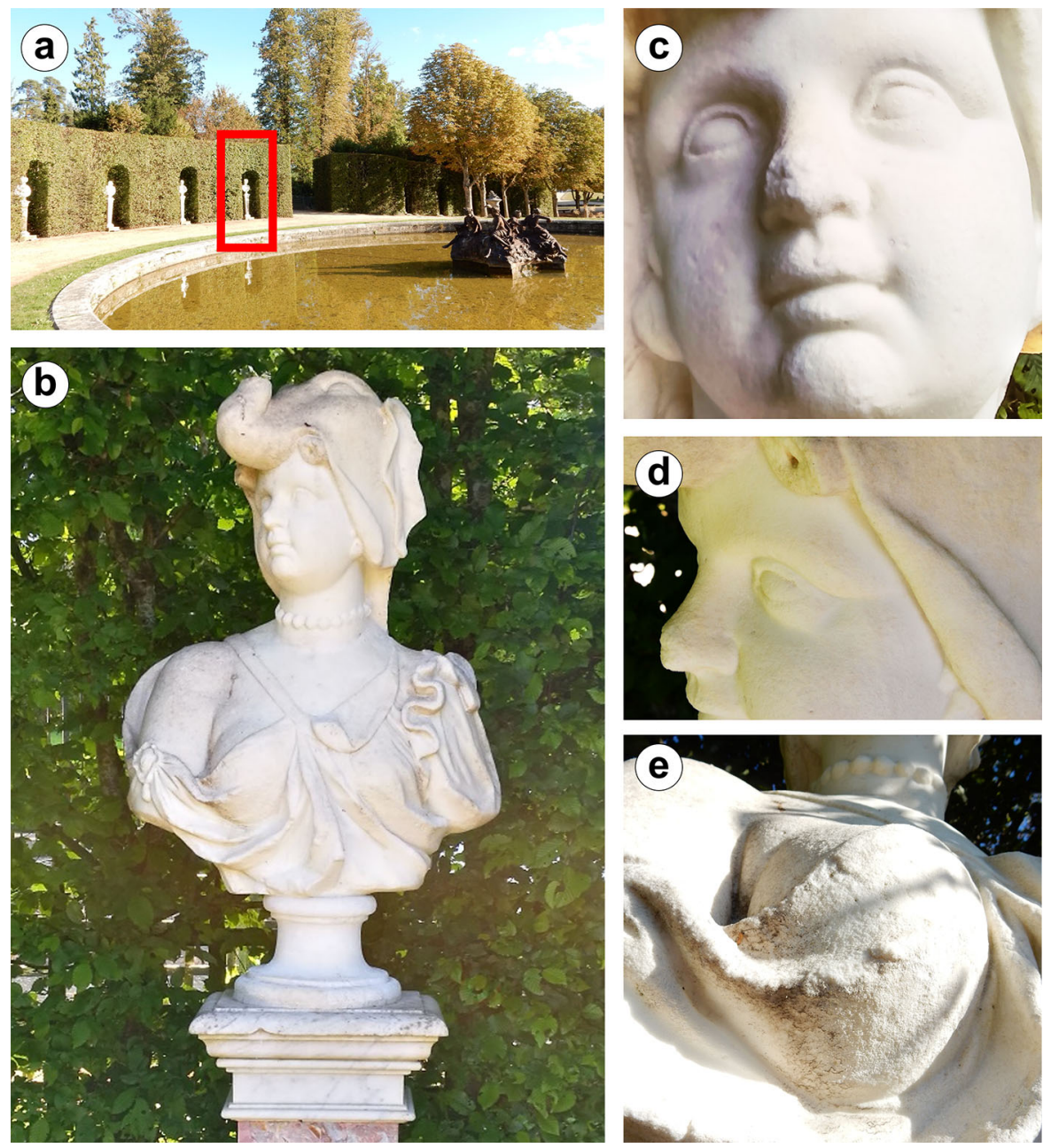

Fig. 3 Sculpture of L'Afrique: a location in the park of the Grand Trianon; $\mathbf{b}$ general view of the bust; details of grain loss affecting the face $\mathbf{c}$, the nose $\mathbf{d}$ and the right breast $\mathbf{e}$ of the bust

\subsubsection{Application method}

As illustrated in Fig. 4, the treatment was applied by poulticing, preceded by spraying of the solution onto the bust, to favor penetration. The poultice was prepared by mixing $8 \mathrm{~L}$ of solutions with dry cellulose pulp, until a poultice with suitable workability was obtained. The poultice was applied onto the bust creating a layer of $\sim 10 \mathrm{~mm}$ thickness. All the bust was covered with the poultice, with the exception of the toroidal pedestal (Fig. 4b). The bust was then wrapped in a plastic film to prevent evaporation (Fig. 4c) and left to react for $24 \mathrm{~h}$. Then, the poultice was removed and the sculpture was rinsed with deionized water to remove poultice residues. In the pedestal, where some solution dripping had occurred, the stone surface was gently brushed with water. After drying, both the bust and the pedestal looked free from deposits (Fig. 4d).

\subsubsection{Characterization}

To evaluate the effectiveness and the compatibility of the treatment, UPV was measured in the points illustrated in Fig. 5a, while WA and $L^{*} a^{*} b^{*}$ color parameters were determined in the positions illustrated in Fig. 5b, in all cases repeating the tests before and after treatment. The same instruments and techniques described in Sect. 2.1.4 were used. All the measurements performed in the field (before and after 

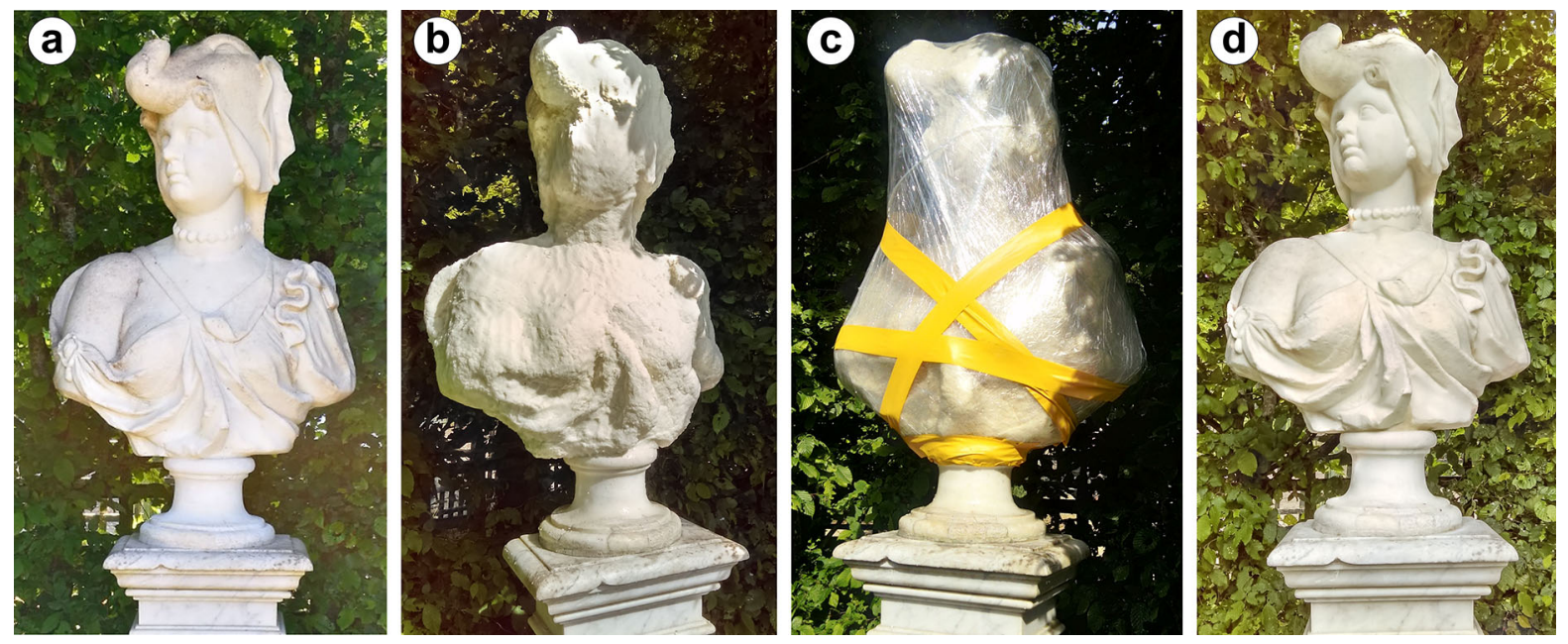

Fig. 4 Phases of bust consolidation: a before treatment; $\mathbf{b}$ after poultice application; $\mathbf{c}$ after wrapping with a plastic film; $\mathbf{d}$ after treatment
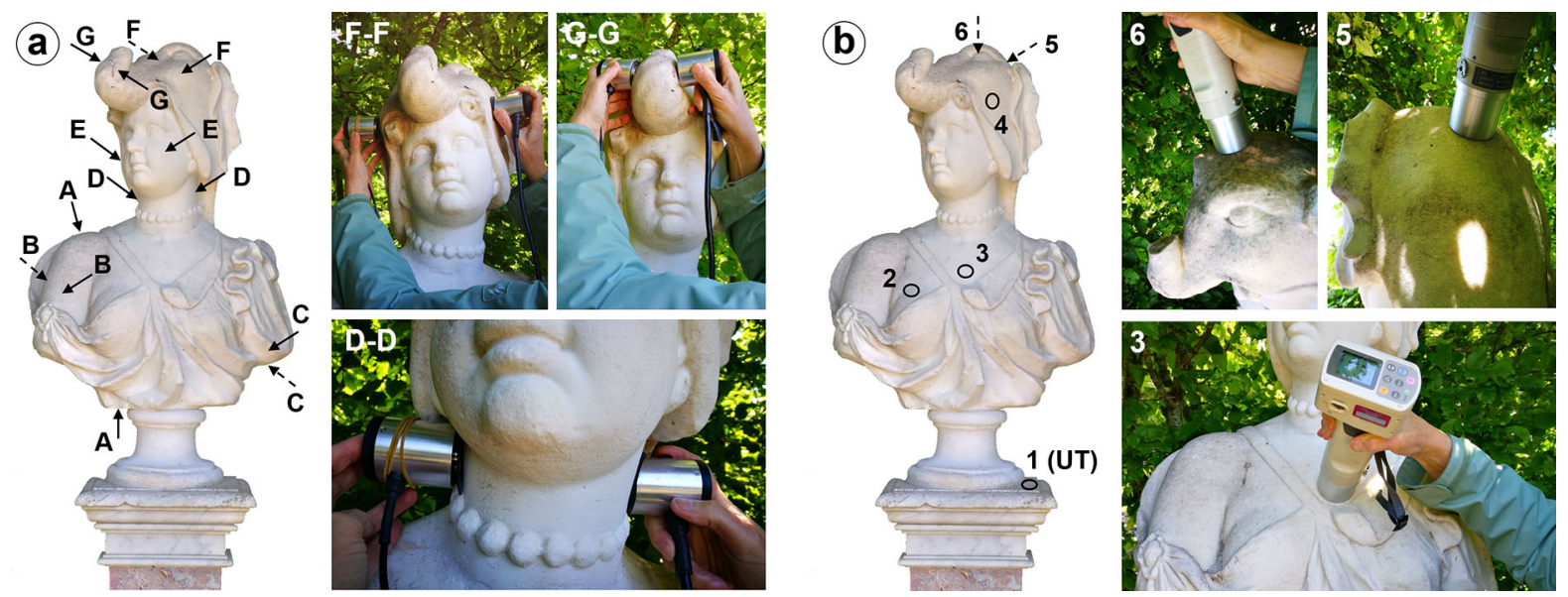

Fig. 5 Schemes and photos illustrating the field measurements on the bust: a ultrasonic tests; $\mathbf{b}$ water absorption and color change (point 1 was left untreated, UT, and used as reference). Dotted arrows indicate measurement points in the rear part of the bust

treatment) were taken after at least 3 days without rain, to prevent as much as possible moisture in the marble pores from altering the measurements.

\subsubsection{Field exposure}

After preliminary characterization, non-destructive tests were repeated 2 months and 25 months after treatment (Fig. 1), based on the availability of the necessary instruments. Because of a malfunction of the UPV instrument, only points B-B, E-E, F-F and $\mathrm{G}-\mathrm{G}$ could be tested after 2 months.
During field exposure, the sculpture was covered in the winter time to prevent deterioration, according to a long-standing practice in the Versailles Park [44]. The sculpture was covered with a woven cotton-polyester cover from November to March of each year. 


\section{Results and discussion}

\subsection{Field testing of the marble specimens}

\subsubsection{Effects of the treatments}

The increase in UPV after treatment (before exposure in the Park) can be seen in Fig. 6 (solid bars). The untreated specimens exhibited the lowest UPV (4.0 $\mathrm{km} / \mathrm{s}$ ), which corresponds to a condition of "increasing porosity" according to the classification proposed by Köhler [45]. All the treated specimens exhibited higher UPV, increasing in the order: "UT" < "EtOH" $<$ "IPA" * "AmOx" < "AlP" < " $1 \mathrm{M} "<" \mathrm{CaCl}_{2}$ " < "3 M". Starting from the least effective treatments, "EtOH" and "IPA" caused modest increases in UPV $(+5 \%$ and $+7 \%$, respectively), actually lower than in previous studies $[13,16]$. This is likely due to the very limited formation of new $\mathrm{CaP}$ phases, as revealed by SEM (only isolated clusters of new $\mathrm{CaP}$ were visible, Fig. 7) and FT-IR (no clear bands ascribable to new CaP were detected, Fig. 8). Such limited formation of new $\mathrm{CaP}$ may be a consequence of the different conditions of this study compared to previous studies, in terms of application technique (poulticing, instead of immersion [16] or brushing [13]) and/or initial marble condition (naturally weathered specimens, instead of artificially weathered but uncontaminated specimens $[13,16])$. The influence of these parameters may be strong when low DAP and $\mathrm{CaCl}_{2}$ concentrations are used, whereas their influence seems lower in the case of more concentrated DAP formulations.
"AmOx" caused an UPV increase (+ 8\%) comparable to "IPA" $(+7 \%)$, thanks to the formation of whewellite, as revealed by SEM (Fig. 7) and confirmed by FT-IR (bands at 1618, 1323, 781, $517 \mathrm{~cm}^{-1}$ [46], Fig. 8). The limited consolidation caused by "AmOx" treatment is consistent with some previous results $[13,15]$, although a higher effectiveness has also been reported $[16,41]$.

"AlP" was a little more effective than "AmOx", reaching $\triangle \mathrm{UPV}=+11 \%$. However, no clear evidence of aluminum phosphate formation was obtained by either SEM (Fig. 7) or FT-IR (Fig. 8), differently from a previous study [39]. Again, this may be a consequence of the different application technique and/or the different condition of the marble substrate in the present case, compared to the previous study [39].

UPV improvements by +14 and $+19 \%$ were achieved after consolidation by " $1 \mathrm{M}$ " and " $\mathrm{CaCl}_{2}$ ", respectively, in agreement with previous studies highlighting the effectiveness of both formulations $[1,16,35,47]$. The benefit of adding $\mathrm{CaCl}_{2}$ as a calcium source, originally pointed out in [21], is here confirmed, both in terms of mechanical effectiveness (Fig. 6) and continuity of the new CaP phases (Fig. 7). In fact, while the new $\mathrm{CaP}$ layer formed over the marble surface exhibits some gap in the case of the " 1 M" treatment, no evident uncovered zones were present in the " $\mathrm{CaCl}_{2}$ " sample. FT-IR results (Fig. 8) suggest formation of HAP (having bands at 1031-1032, 602-604 and 561-563 $\mathrm{cm}^{-1}$ [48, 49]), consistently with previous findings [21]. In the case of the " $\mathrm{CaCl}_{2}$ " treatment, a shift in the FT-IR band from

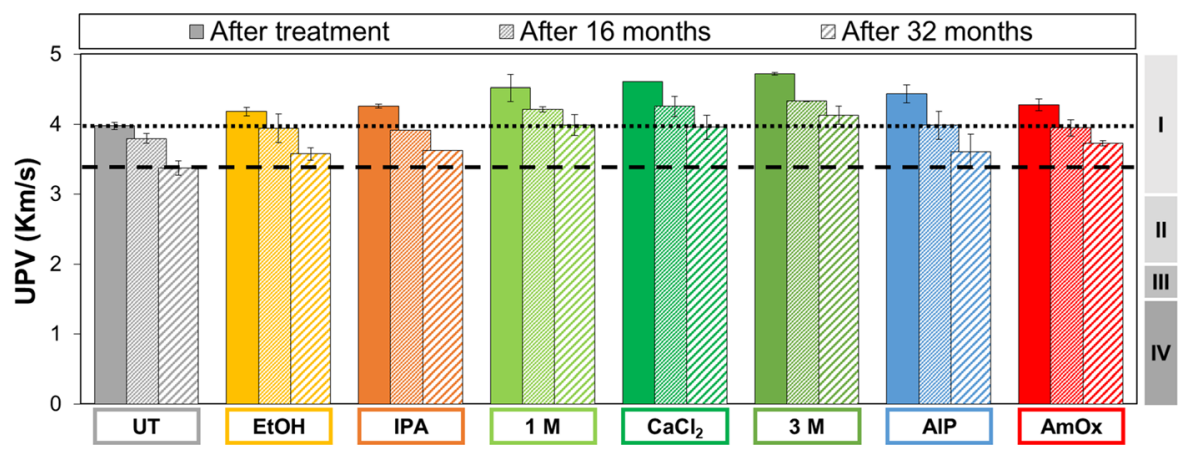

Fig. 6 UPV values of untreated and treated specimens after consolidation (solid bars) and after field exposure for 16 months (densely hatched bars) and 32 months (sparsely hatched bars). Dotted and dashed lines indicate the values of the untreated references after treatment and after 32 months, respectively.
Bars on the right indicate the categories (I-IV) of marble deterioration according to the classification proposed by Köhler [45]. Values are averages for 2 replicates (bars indicate the difference between the average and the maximum/minimum values) 


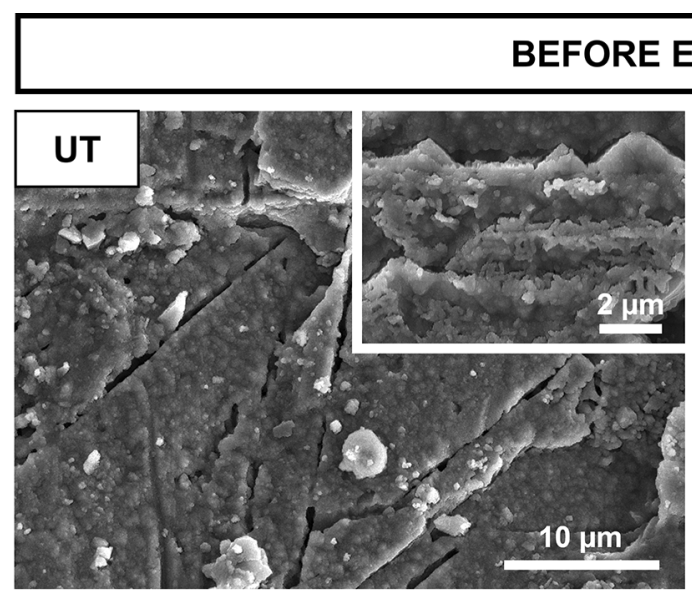

\section{EXPOSURE}
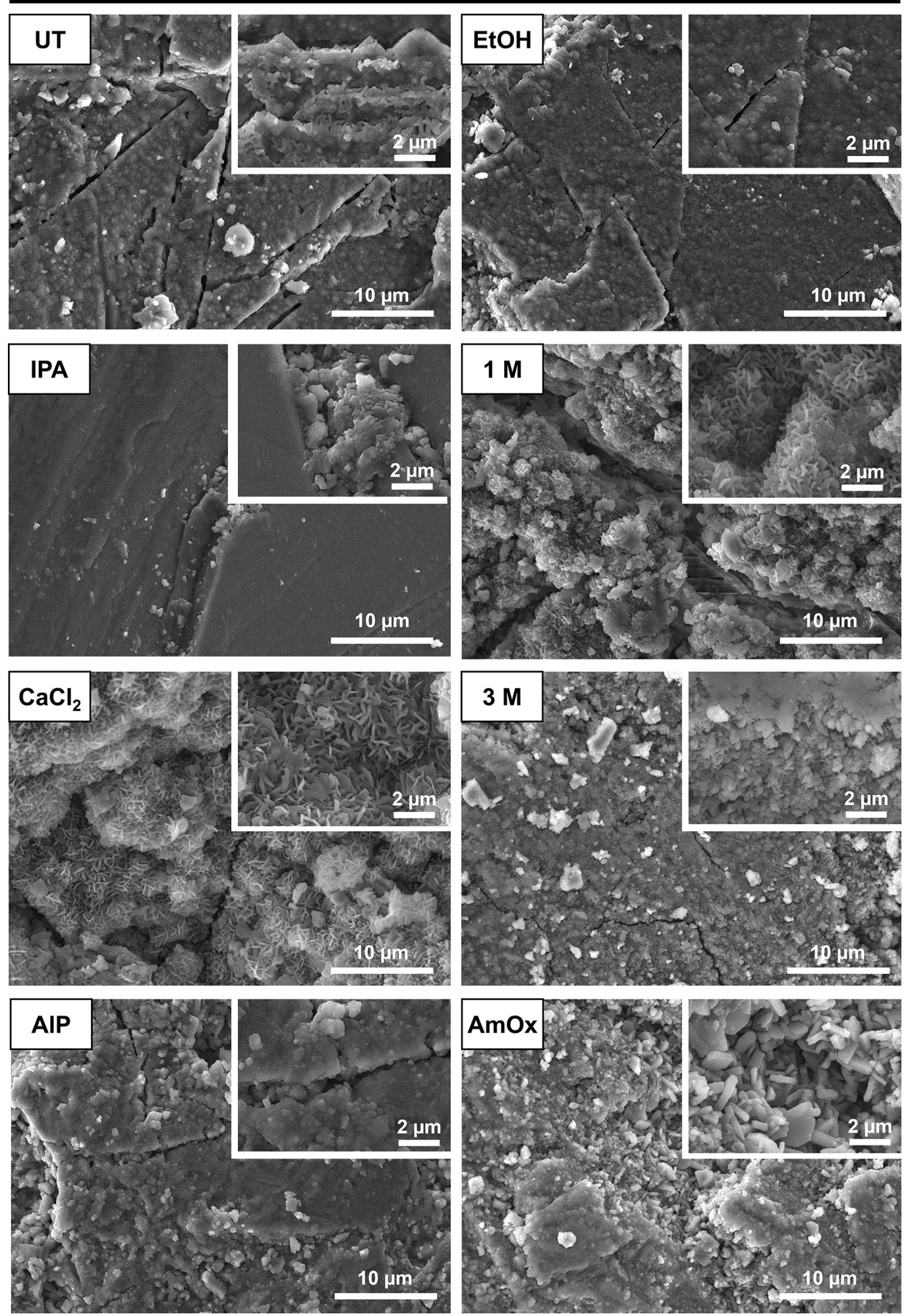
४Fig. 7 SEM images of untreated and treated specimens, before field exposure

1027 to $1037 \mathrm{~cm}^{-1}$ occurred, which may be a signal that, alongside HAP, also octacalcium phosphate (OCP, having bands at 1023-1026, 1036-1038, 602-603 and $\left.560 \mathrm{~cm}^{-1}[48,49]\right)$ may have formed. Formation of both HAP and OCP is likely, considering that the addition of a calcium source permits less stable OCP to form [21]. In spite of being more soluble than HAP, OCP is however sensibly less soluble than calcite [21], hence its formation is expected to cause long-lasting consolidating and protective actions. It is noteworthy that the addition of $\mathrm{CaCl}_{2}$ as a calcium source did not lead to significant free chlorides in any specimen, because basically the same amount of $\mathrm{Cl}^{-}$ ions was found in untreated and treated specimens (Table S1).

The highest UPV increase was registered for the "3 M" formulation ( $\triangle \mathrm{UPV}=+19 \%)$, consistently with previous results [13, 15, 27, 39]. This high strengthening ability is due to the abundant formation of new CaP phases, as indicated by SEM (Fig. 7) and FT-IR (Fig. 8). These new phases effectively bond calcite grains, even though pores and cracks have been reported in the new $\mathrm{CaP}$ phases [3].

As a consequence of $\mathrm{CaP}$ formation, variations in pore size distribution (Fig. 9) and water absorption (Fig. 10) were registered. All the treatments caused some alteration in the pore system, especially a reduction in the amount of bigger pores, but in no case was marble porosity completely occluded (Fig. 9). The lack of significant pore occlusion is important as it ensures the possibility for calcite grains to deform upon temperature variations, without stress arising at the grain boundaries [13]. Consistently, some reduction in water absorption was registered, however without any dramatic decrease (Fig. 10). The alterations in WA were mostly consistent with the increases in UPV. "IPA" and "AlP" led to modest consolidation, as a consequence of limited formation of new phases, and also limited WA reductions by $10-12 \%$ (Fig. 10). "EtOH" is apparently an exception, because an average WA reduction by $42 \%$ was registered. However, a strong difference exists between the two replicates (reductions by $10 \%$ and by $74 \%$ for the two specimens). Most likely the latter measurement was biased, so the former result (in line with the "IPA" and "AlP" specimens) is likely more reliable. The " $1 \mathrm{M}$ ", " $\mathrm{CaCl}_{2}$ " and " $3 \mathrm{M}$ " treatments, which caused the highest UPV increases (Fig. 6) and the most abundant CaP formation (Figs. 7 and 8), also exhibited the highest WA reductions by $36-43 \%$ (Fig. 10). A similar WA reduction (-43\%) was shown also by "AmOx", which however exhibited lower consolidating effectiveness (Fig. 6). The WA variations assessed in the present study are in good agreement with the values reported for the same formulations in previous studies [1, 39].

However, when evaluating these WA alterations, it should be considered that a not negligible increase in WA $(+25 \%$, Fig. 10) was found also for the untreated reference (re-tested only to check the measurement repeatability). This increase was attributed to the different amounts of moisture present in the specimen when the WA measurements were taken, before and after consolidation. The possible influence of hygroscopic salts was excluded, because ion chromatography did not reveal any significant amount of ions ascribable to soluble salts. To prevent uncontrolled amounts of moisture in the pores from altering the measurements, when WA was assessed during field exposure the specimens were pre-conditioned as described in Sect. 2.1.5.

After treatment, the specimens also exhibited some alterations in the color parameters (Table S2), resulting in the overall color change reported in Fig. 11. Also the untreated reference exhibited $\Delta E^{*}=1.9$, mostly due to an increase in lightness $\Delta L^{*}=1.8$ (Table S2). Although below the human eye detection limit $\left(\Delta E^{*}=2.3[50]\right)$, this color change was still unexpected and likely due to a different moisture content when the measurements were taken. Except for "AmOx", all the treatments caused modest color changes $\left(\Delta E^{*}=2.0-3.5\right)$, in all cases below the threshold commonly accepted for conservation treatments $\left(\Delta \mathrm{E}^{*}=5[51]\right)$. In particular, the phosphate treatments involving low DAP concentrations ("EtOH", "IPA" and also "AlP") caused some increase in lightness $\left(\Delta L^{*}\right.$ ranging from 1.9 to 2.8 , Table S2) and minor decreases in the $a^{*}$ and $b^{*}$ parameters (ranging from -0.3 to -0.6 , Table S2). On the contrary, the formulations involving higher DAP concentrations ("1 M", " $\mathrm{CaCl}_{2}$ " and "3 M") caused some decreases in lightness $\left(\Delta L^{*}\right.$ ranging from -1.8 to -3.3 , Table S2) and some increases in 
Fig. 8 FT-IR spectra of untreated and treated specimens, before and after field exposure. Bands owing to the marble substrate are marked by a star while the position of bands owing to newly formed phases is specified. Bands in the "1 M" sample can be ascribed to hydroxyapatite (HAP, having bands at 1031-1032, 602-604 and $\left.561-563 \mathrm{~cm}^{-1}[48,49]\right)$.

Bands in the " $\mathrm{CaCl}_{2}$ " sample can be ascribed to octacalcium phosphate (OCP, having bands at 1023-1026, 1036-1038, $602-603$ and $560 \mathrm{~cm}^{-1}$ $[48,49])$. Bands in the " 3 M" sample are likely to be ascribed to OCP. Bands in the "AmOx" sample can be ascribed to whewellite (having bands at 1618, 1323, $781,517 \mathrm{~cm}^{-1}$ [46])

\section{Before exposure}
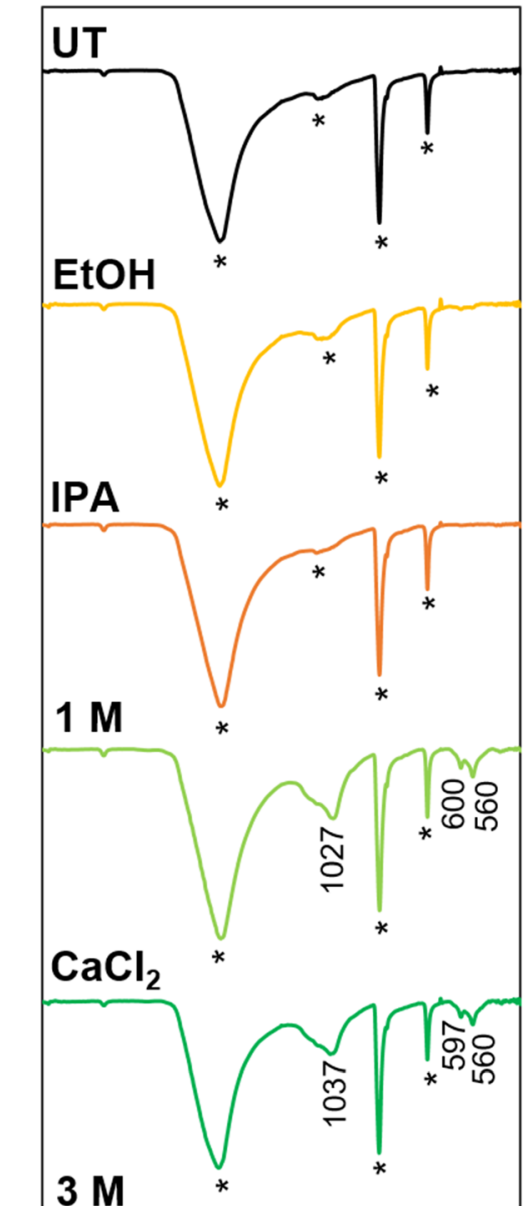

$3 \mathrm{M}$
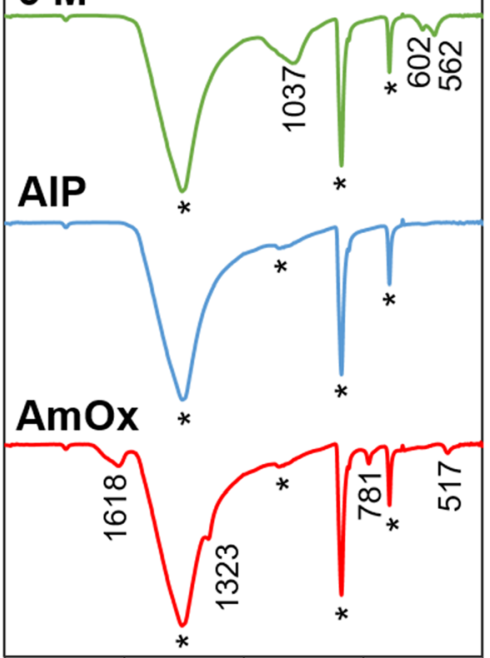

$2000 \quad 1600 \quad 1200 \quad 800 \quad 400$

Wavenumber $\left(\mathrm{cm}^{-1}\right)$

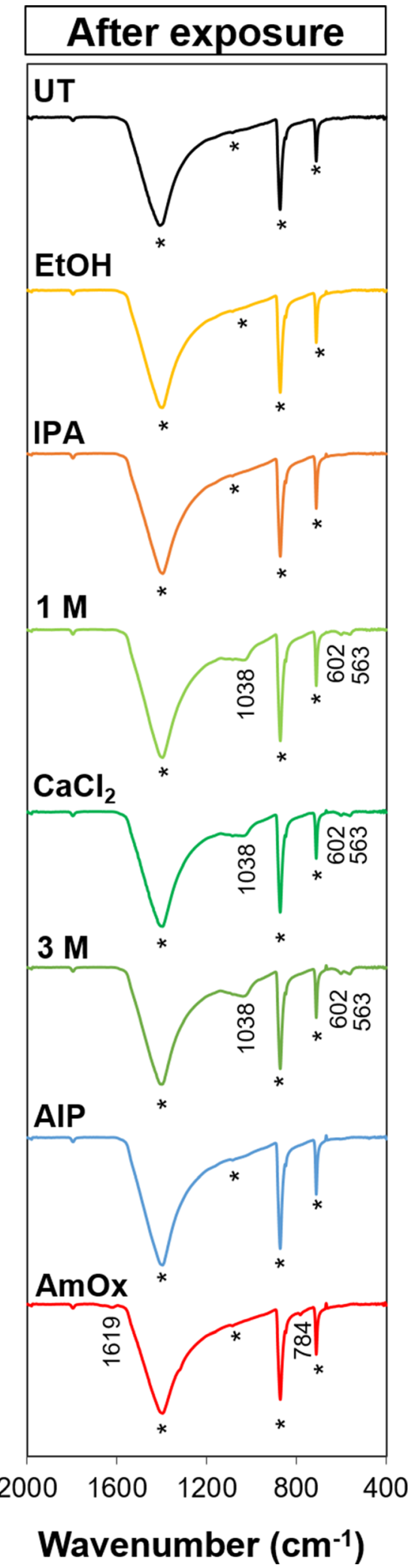



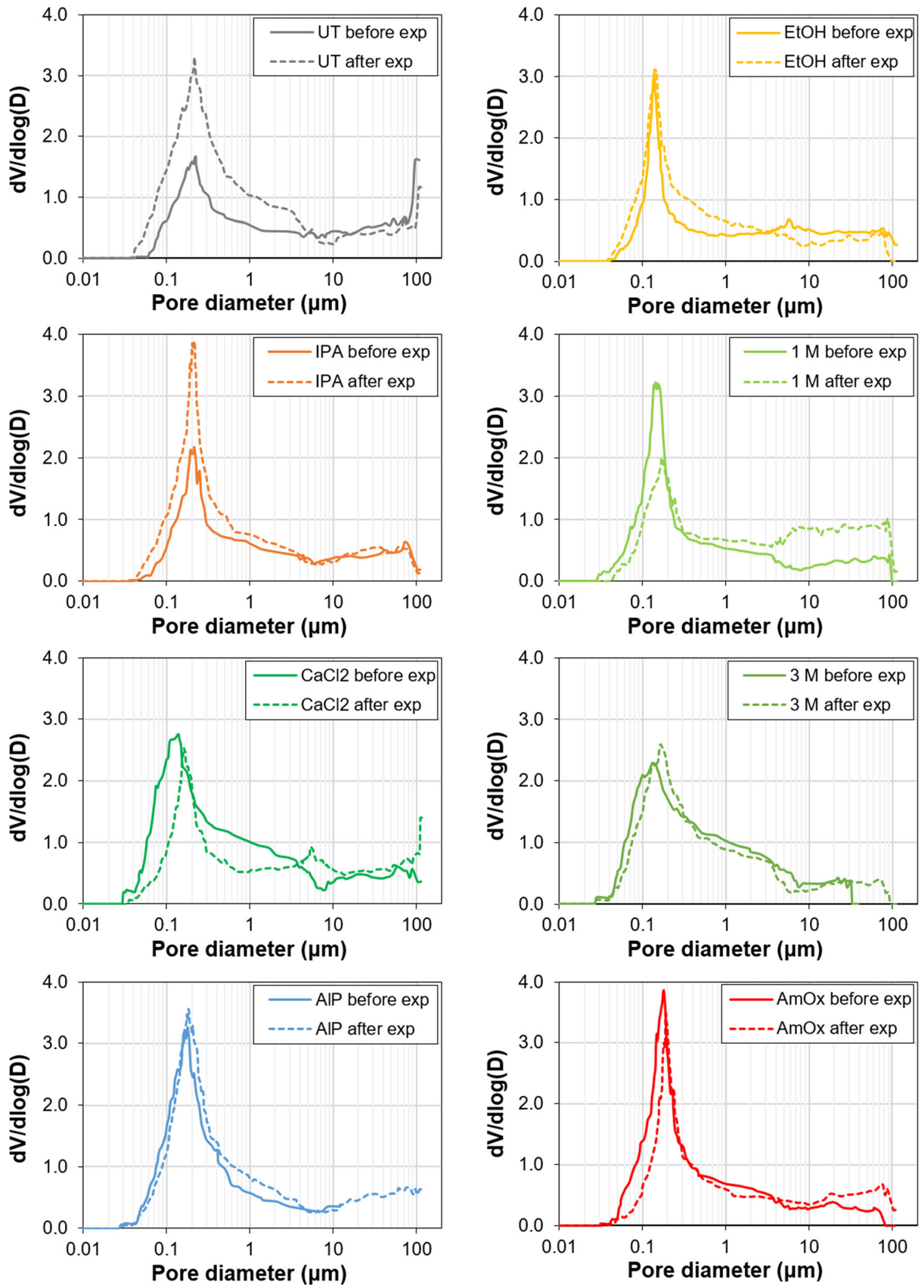
4Fig. 9 Pore size distribution of untreated and treated specimens, before (solid lines) and after (dotted lines) field exposure for 32 months

the $a^{*}$ and $b^{*}$ parameters (ranging from 0.5 to 1.2 , Table S2). Different from the phosphate treatments, "AmOx" was responsible for $\Delta E^{*}=10.5$, largely due to a decrease in lightness $\left(\Delta L^{*}=-5.5\right.$, Table S2) and shift towards yellow ( $\Delta b^{*}=8.8$, Table S2). This was unexpected considering that the "AmOx" treatment is known to generally cause modest color alterations, with only some increase in color saturation [41]. A possible reason for the color change registered in this case may be in the initial condition of the marble surface, presenting a pale yellow patina (Fig. 2).

\subsubsection{Effects of field exposure}

After 16 months, all the specimens exhibited a reduction in UPV by $5-10 \%$ (Fig. 6, densely hatched bars). These UPV reductions can be ascribed to natural weathering processes occurring in the field, in particular: (i) freezing-thawing cycles, leading to microcrack formation (the analysis of environmental data pointed out that, during the exposure period, on at least 63 days conditions for freezing-thawing cycles occurred, but the total number of cycles was likely higher as freezing-thawing might have taken place more than once in a day); (ii) heating-cooling cycles during summertime, leading to microcrack formation, especially if moisture is present in the pores [52]; (iii) rainfall, leading to dissolution of uncoated areas and

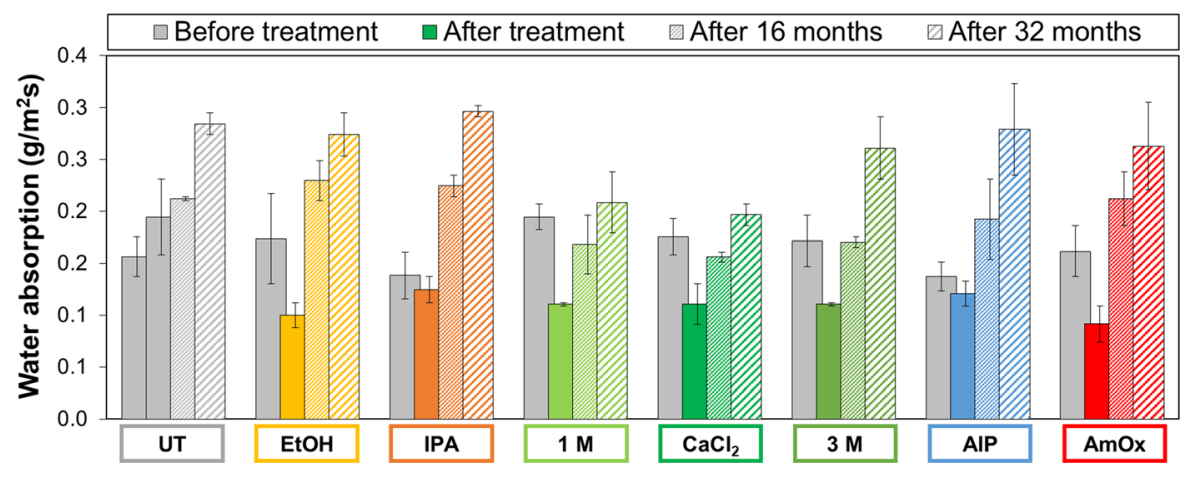

Fig. 10 Water absorption of untreated and treated specimens, before consolidation (solid gray bars), after consolidation (solid colored bars) and after field exposure for 16 months (densely hatched bars) and 32 months (sparsely hatched bars). Values are averages for 2 replicates (bars indicate the difference between the average and the maximum/minimum values). (Color figure online)

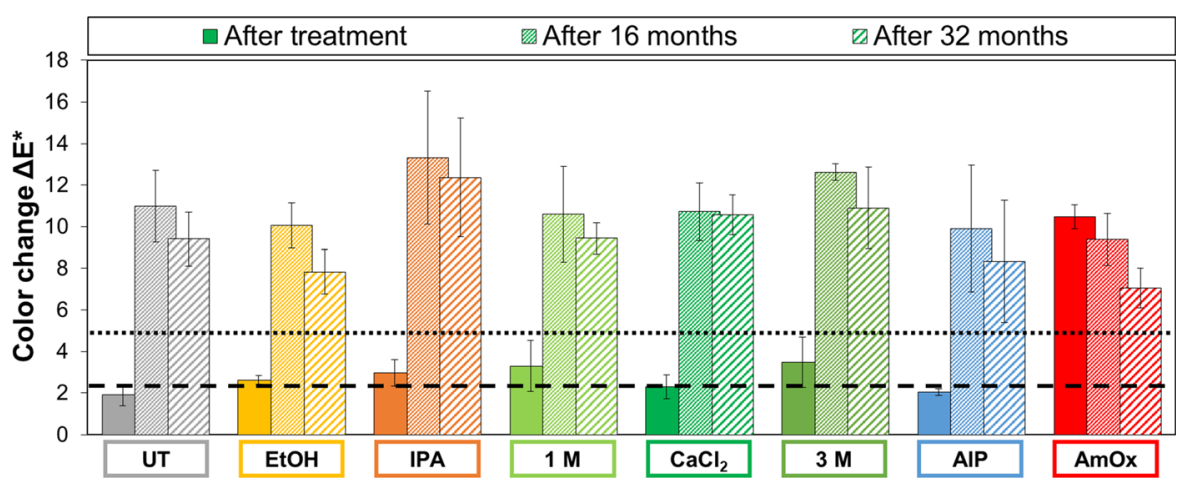

Fig. 11 Color change of untreated and treated specimens after consolidation (solid bars) and after field exposure for 16 months (densely hatched bars) and 32 months (sparsely hatched bars). The dashed line $\left(\Delta E^{*}=2.3\right)$ indicates the threshold of detectability by the human eye [50], while the dotted line $\left(\Delta E^{*}=5\right)$ indicates the common acceptability threshold [51]. Values are averages for 2 replicates (bars indicate the difference between the average and the maximum/minimum values) 
damage caused by rain drops hitting the specimen surface. In addition to natural weathering, in this specific case the possible influence of specimen preconditioning cannot be completely excluded. Although designed not to damage the specimens, moisture removal by pre-conditioning at $65^{\circ} \mathrm{C}$ for $48 \mathrm{~h}$ (Sect. 2.1.5) might have caused localized thermal stress, resulting in crack formation and UPV reduction [52]. Although not specifically verified experimentally, crack formation after heating at $65{ }^{\circ} \mathrm{C}$ is possible, considering that separation of calcite grains after heating at a temperature as low as $45^{\circ} \mathrm{C}$ has been observed in the literature [53].

However, a further UPV decrease was experienced passing from 16 to 32 months (Fig. 6, sparsely hatched bars). Pre-conditioning was performed in the same way in these two occasions and re-heating at the same temperature is not expected to cause additional thermal damage [54]. In fact, when marble is heated to a certain temperature, calcite crystals undergo anisotropic thermal deformation and stress arises at grain boundaries, resulting in the formation of new intergranular fissures. When marble is cooled down and then re-heated at the same temperature, the voids formed after the first heating are able to accommodate calcite crystals deformation without significant new stress and without formation of additional new cracks [54], thus exerting a sort of "buffering effect" [55]. Therefore, in the present case the further UPV decrease passing from 16 to 32 months can be mainly ascribed to natural weathering, because pre-conditioning at the same temperature should not cause formation of additional cracks.

According to UPV measurements, SEM observations performed after 32 months (Fig. 12) revealed etching of the marble surface not only in the untreated reference, but also in the "EtOH", "IPA", "1 M", "AlP" and "AmOx" specimens, which indicates significant damage and removal of the new consolidating phases in these specimens. The detachment of the consolidating phases was likely triggered by some discontinuity in the new coatings covering the calcite grains, as a consequence of some defect originally present in the coating and/or the action of environmental weathering processes. Once the detachment of the coatings had started from these weak areas, the combined action of rainwater and thermal stress likely led to the removal of the consolidating phases. Consistently, FT-IR analysis of the "EtOH", "IPA" and "AlP" samples revealed no bands ascribable to $\mathrm{CaP}$ phases, while the band intensity was strongly diminished in the "1 M" and "AmOx" samples (Fig. 8).

After 32 months, the only treatments for which the new $\mathrm{CaP}$ phases were still clearly distinguishable by SEM (Fig. 12) and FT-IR (Fig. 8) were " $\mathrm{CaCl}_{2}$ " and, even more, "3 M". Although cracks and uncoated areas appeared and FT-IR bands decreased in intensity, clear signs of the consolidating phases were detected. Consistently, after 32 months the " $3 \mathrm{M}$ ", " $\mathrm{CaCl}_{2}$ " and " $1 \mathrm{M}$ " specimens still exhibited a residual UPV (4.0-4.1 km/s) similar to the "UT" reference before field exposure $(4.0 \mathrm{~km} / \mathrm{s})$ and sensibly higher than the "UT" reference after 32 months (3.4 $\mathrm{km} / \mathrm{s}$ ) (Fig. 6). Therefore, application of these formulations was not sufficient to completely prevent marble damage, but still was able to mitigate damage, leading to a significant residual benefit after 32 months.

A similar trend was found by MIP (Fig. 9) and WA (Fig. 10). After 16 and 32 months, all the specimens underwent a progressive increase in WA, which is a sign of progressive formation of new cracks, also responsible for the progressive decrease in UPV. For "UT", the WA increase was higher between 16 and 32 months, compared to the first 16 months, which suggests that the weathering effect of field exposure was predominant over damage possibly occurred during pre-conditioning. In "UT", a substantial alteration in pore size distribution and open porosity (increased from 0.59 to $0.93 \%$ ) was assessed by MIP. Notably, after 32 months the " $\mathrm{CaCl}_{2}$ ", " $1 \mathrm{M}$ " and " 3 M" specimens exhibited lower WA than the "UT" reference, in accordance with the UPV results. This mitigating effect is sensibly more effective than in the case of alternative treatments, including "AmOx".

Unlike UPV and WA, the color measurements during field exposure did not show a clear progressive trend (Fig. 11). After 16 months, all the specimens exhibited a strong increase in $L^{*}$ (whitening), while after 32 months $L^{*}$ strongly decreased (darkening), thus inverting the previous trend. Such unintuitive behavior is likely due to specimen pre-conditioning before the measurement, rather than to field exposure. In fact, the first pre-conditioning in oven likely caused some microcrack formation, with a consequent change in the scattering of light and apparent whitening. When the measurement was repeated after 32 months, pre-conditioning at the same temperature did not cause 


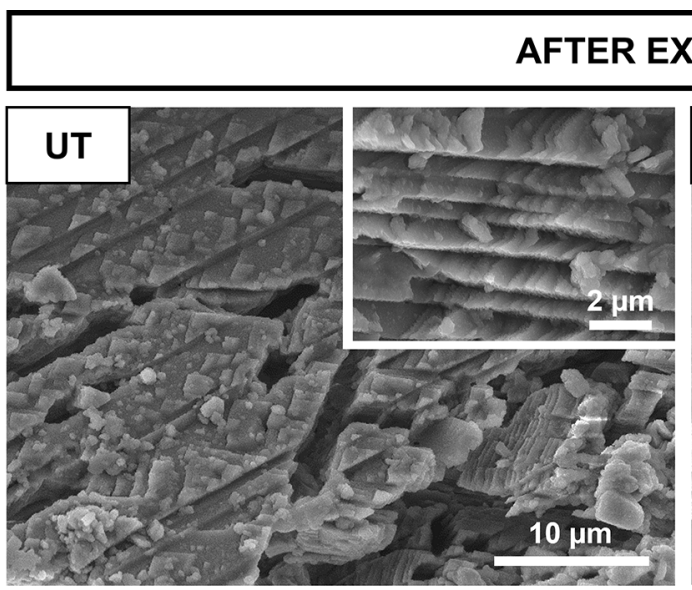

\section{AFTER EXPOSURE}
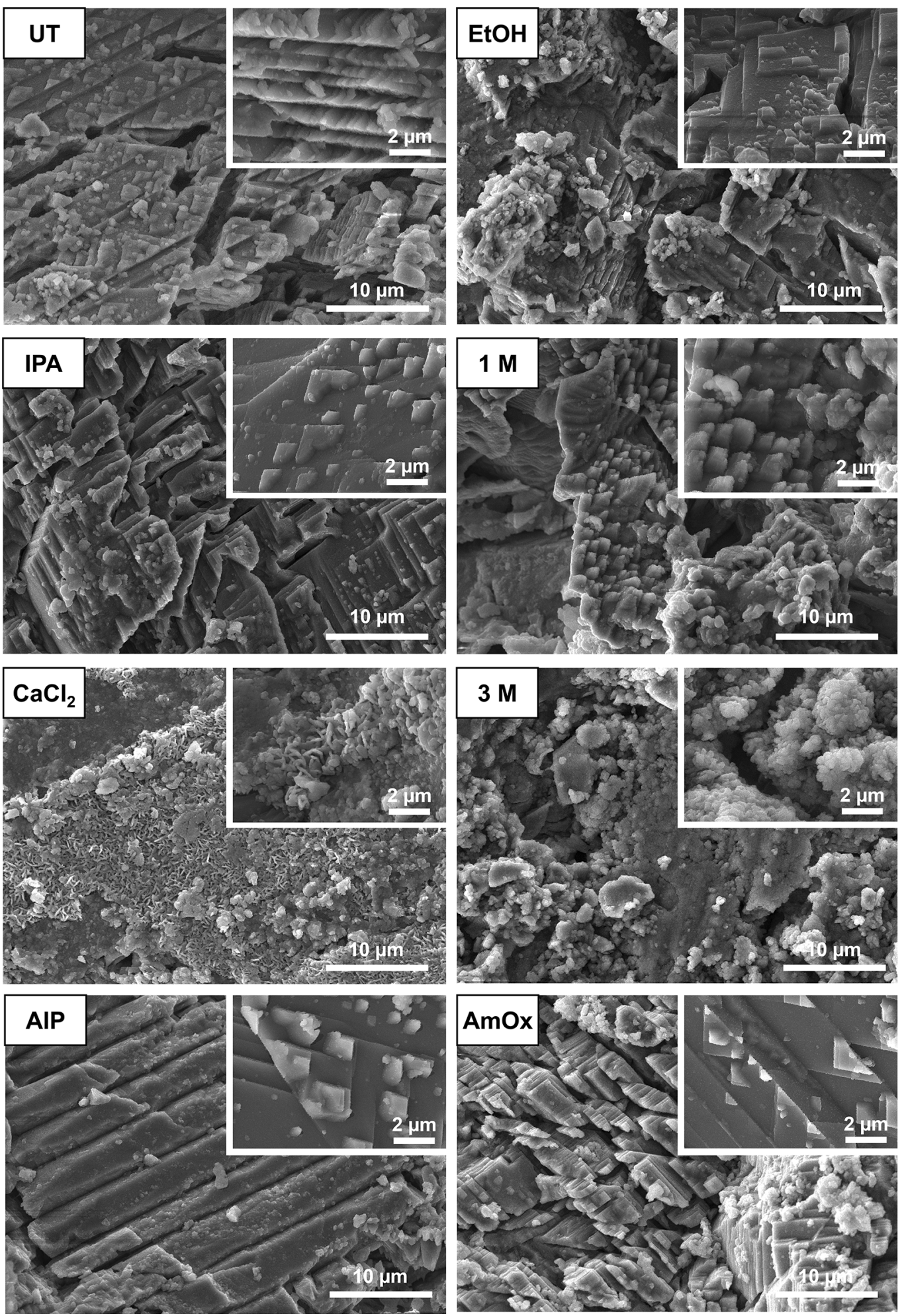
४Fig. 12 SEM images of untreated and treated specimens, after field exposure

further crack formation, while field exposure caused some dirt accumulation and darkening.

It is important to note that in none of the specimens was biological growth detected on the exposed face (which was the treated face in the case of the consolidated specimens) by either visual examination or FT-IR, while some biological growth was observed on the opposite face (in contact with the specimen holder). Therefore, it can be concluded that none of the treatments was responsible for promoting biological growth.

\subsection{Field testing of the marble sculpture}

\subsubsection{Effects of treatment}

Before treatment, UPV ranged between 2.7 and $4 \mathrm{~km} / \mathrm{s}$ (Fig. 13, solid gray bars), thus between the conditions of "increasing porosity" and "crumbling surface" proposed by Köhler [45]. Such low UPV values are not surprising, considering that the sculpture has been exposed outdoors for more than three centuries. The lowest values were measured in the left arm (point $\mathrm{C}-$ C) and in the elephant nose (point $\mathrm{G}-\mathrm{G}$ ), hence in thin elements that are usually more prone to thermal deterioration as they follow environmental temperature fluctuations more closely [26].

Two months after application of the " $\mathrm{CaCl}_{2}$ " treatment, the UPV increases (Fig. 13, solid green bars) were sensibly lower than those measured in the prismatic specimens after the same treatment. In fact, UPV improvements by $+19 \%$ were registered in the specimens (Fig. 6), whereas a maximum UPV increase of $+6 \%$ was found in the bust, specifically in the elephant nose (point G-G, Fig. 13). This difference is thought to be due to the treatment penetration depth, which based on previous studies can be estimated as 10-20 mm [15, 16]. In the specimens (30 mm thick), consolidation of the first $10-20 \mathrm{~mm}$ from the treated surface led to a high UPV increase, as the consolidated layer was about $1 / 3-2 / 3$ of the path travelled by the ultrasonic pulse. In the sculpture, where the path of the ultrasonic pulse was generally much higher than 30 $\mathrm{mm}$, an analogous 10-20 mm thick consolidated layer had a much lower influence on the measured UPV. A similar effect occurs when UPV is used to evaluate the weathering condition of marble elements in the field, as the shorter the travelling path of the ultrasonic pulse, the higher the reduction in UPV caused by surface damage [56]. In some of the measuring points (B-B and F-F), slight UPV decreases by $1-4 \%$ were found, which seems likely due to the measurement reproducibility in the field, rather than to actual deterioration occurred after just 2 months of field exposure.

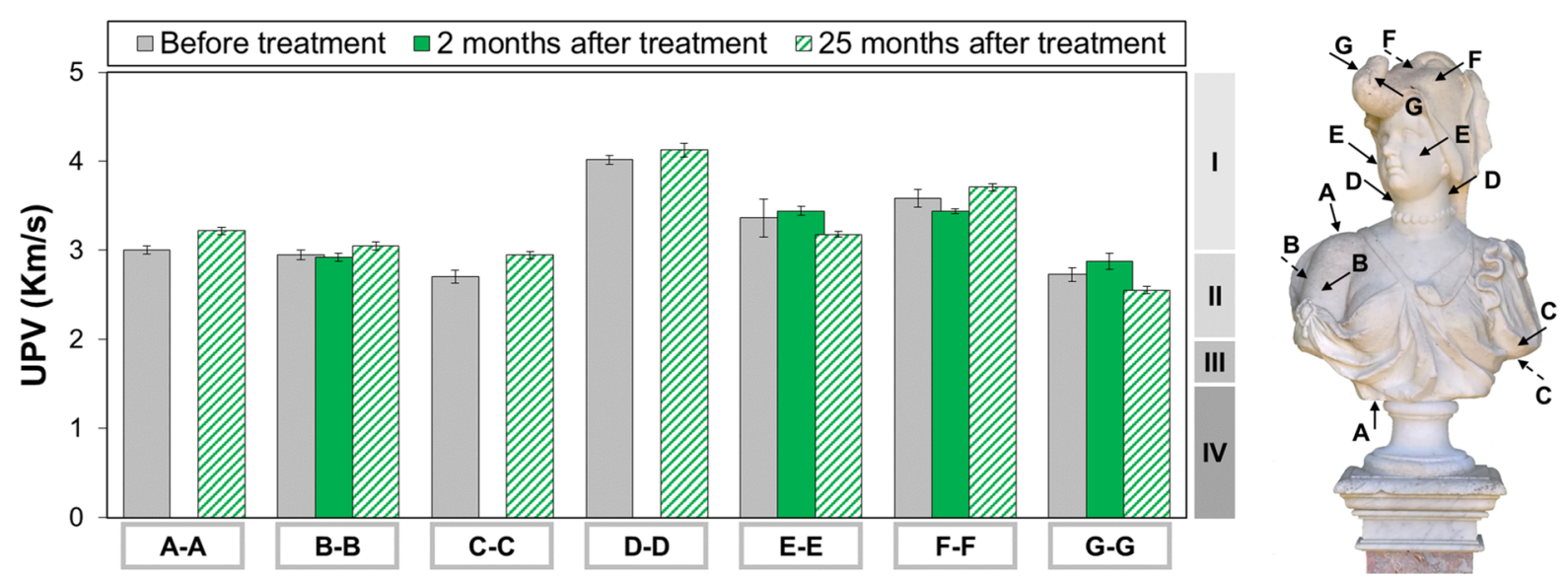

Fig. 13 UPV values measured on the bust in the positions indicated on the right, before (solid gray bars), 2 months after treatment (solid green bars) and 25 months after treatment (hatched bars). Bars on the right indicate the categories (I-IV) of marble deterioration according to the classification proposed by Köhler [45]. Values are averages for 2 measurements (bars indicate the difference between the average and the maximum/ minimum values). (Color figure online) 
After treatment, water absorption reductions ranging from -13 to $-27 \%$ were registered in all the measuring points (Fig. 14), in line with the WA reduction found in the specimens after the same treatment (-37\%, Fig. 10). This confirms the compatibility of the " $\mathrm{CaCl}_{2}$ " treatment, which causes some reduction in WA without compete pore occlusion. Point 1 in the pedestal (Fig. 14), which was left untreated and used as reference, actually exhibited a slight increase in WA, likely because cleaning of this area right before the WA and color measurements exposed the stone surface.

In fact, two months after treatment the untreated reference area (point 1) exhibited the highest color change $\left(\Delta E^{*}=10.7\right.$, Fig. 15$)$, mostly because of a strong increase in $L^{*}$ (whitening, Table S3). This color change can be ascribed to a cleaning campaign carried out between the two colorimetric measurements. The cleaning campaign, consisting in washing with water and brushing, likely removed surface dust and deposits, thus resulting in a whiter color and higher water absorption when the measurements were repeated. The treated points exhibited different color alterations, ranging from invisible to higher than the common acceptability limit (Fig. 15). Similar to the untreated reference, all the measuring points experienced an increase in $L^{*}$ (Table S3), together with a general decrease in $a^{*}$ and $\mathrm{b}^{*}$ (shift towards green and blue, respectively, Table S3). Unexpectedly, points that had similar initial conditions (e.g., points 2 and 3 or points 5 and 6 ) gave different color alterations. This is thought to be mainly due to the different specific conditions of the various points (e.g., inclination with respect to the horizontal, exposure towards the open air or towards the hedge, initial roughness of the marble surface), leading to differences in dust accumulation and/or possible biological growth. In summary, after the " $\mathrm{CaCl}_{2}$ " treatment variable color changes, ranging from invisible to clearly visible (whitening), were registered depending on the analyzed area. Because 2 months had passed between the consolidant application and the colorimetric measurement after treatment and because the sculpture had been cleaned during this time, in the case of the sculpture it is hard to isolate the effect of the consolidating treatment from the effect of field exposure.

\subsubsection{Effects of field exposure}

After 25 months, the UPV values reported in Fig. 13 (sparsely hatched bars) were registered. All the points that could not be measured right after treatment but were measured after 25 months exhibited slightly higher UPV than before treatment, with increases between +3 and $+9 \%$ (the maximum being registered in the most decayed part, point $\mathrm{C}-\mathrm{C}$ ). In the points already characterized after treatment, some UPV increases (points B-B and F-F) and some UPV decreases (points $\mathrm{E}-\mathrm{E}$ and $\mathrm{G}-\mathrm{G}$ ) were registered. Considering all the tested points, it can be concluded that after 25 months the phosphate treatment generally

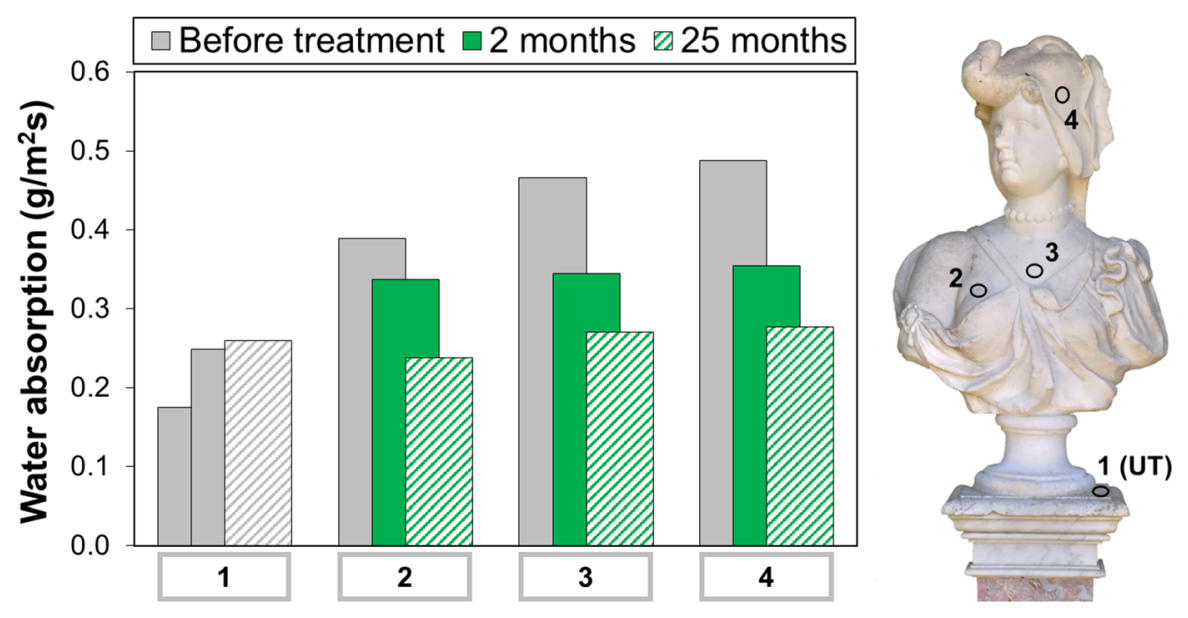

Fig. 14 Water absorption measured on the bust in the positions indicated on the right, before (solid gray bars), 2 months after treatment (solid colored bars) and 25 months after treatment (hatched bars). The position 1 was left untreated and used as reference. (Color figure online) 

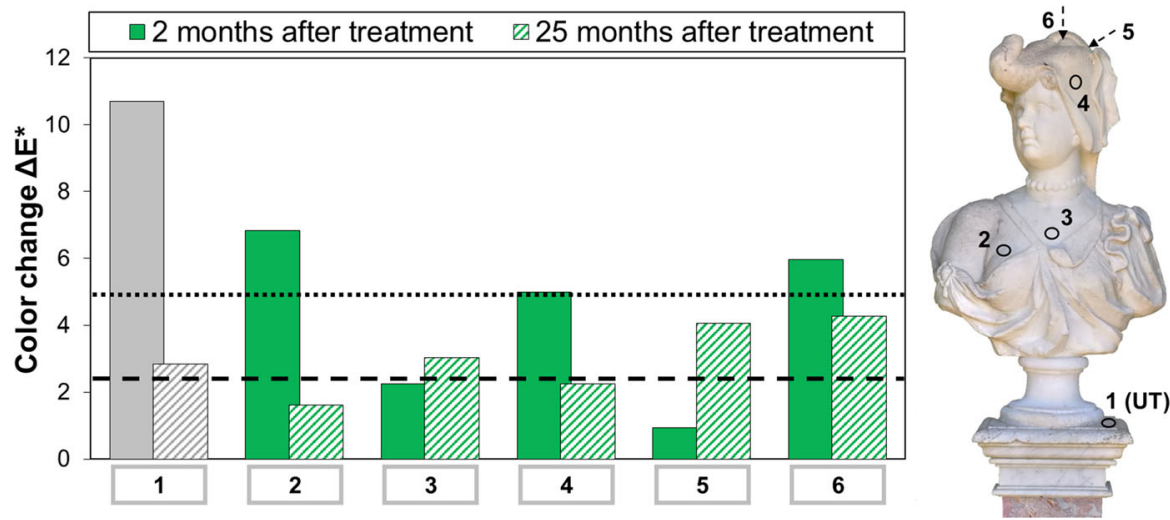

Fig. 15 Color change measured on the bust in the positions indicated on the right, 2 months (solid bars) and 25 months after treatment (hatched bars). The dashed line $\left(\Delta E^{*}=2.3\right)$ indicates the threshold of detectability by the human eye [50], while the

caused some slight improvement in cohesion, although the effect is not very evident. The treatment effects were most pronounced in the most decayed parts of the sculpture, which corresponded to the thinnest parts where the treatment penetration depth influences the UPV measurement the most. The lack of a clear trend in UPV variation over time suggests the difficulty of repeating the measurement exactly in the same point and in exactly the same conditions over time.

All the measuring points exhibited a general slight reduction in WA (Fig. 14) and a decrease in the $L^{*}$ parameter (Table S3). This darkening may be ascribed to deposition of particulate matter on the sculpture surface, with a reduction in water penetration into the pores. Notably, 25 months after treatment the combined action of dust accumulation, cleaning by rainfall and periodical cleaning by the restorers of the Royal Palace led to the final color of the sculpture being very close to the initial one before treatment. In all the points, the final change was below the common acceptability threshold and in some cases even below the human eye detectability threshold (Fig. 15).

\section{Conclusions}

The results of the present study, aimed at evaluating for the first time the long-term performance of several formulations of the phosphate treatment applied onto marble specimens and a marble sculpture exposed in dotted line $\left(\Delta E^{*}=5\right)$ indicates the common acceptability threshold [51]. The position 1 was left untreated and used as reference

the Versailles Park, allow to derive the following conclusions:

- Right after treatment, the consolidating effect measured on the specimens was higher for more concentrated phosphate solutions, as a consequence of more abundant formation of new calcium phosphate phases. These new phases caused some limited alterations in pore size distribution, water absorption and aesthetic appearance. In fact, the most concentrated phosphate solutions caused some decrease in lightness (darkening) and a slight shift towards red and yellow, but the resulting color changes were always below the common acceptability threshold.

- During exposure in the Versailles Park, all the specimens exhibited a progressive decrease in cohesion and increase in water absorption as a consequence of natural weathering, with also a possible contribution from pre-conditioning in oven before the measurements. After 32 months, the new consolidating phases formed after the phosphate treatments with low concentrations, as well as after the ammonium oxalate treatment, had been mostly detached and removed, likely because of some discontinuity originally present in the consolidating phases and/or caused by natural weathering. Differently, in the case of the " $\mathrm{CaCl}_{2}$ " and " $3 \mathrm{M}$ " treatments the new consolidating phases were still present after 32 months, as assessed by FT-IR and SEM. Consistent with the permanence of the phosphate phases, a mechanical 
benefit was still present in the " $\mathrm{CaCl}_{2}$ " and " $3 \mathrm{M}$ " specimens after 32 months (higher UPV than the untreated reference). These results indicate that, even though marble weathering was not completely inhibited, still the phosphate treatments were able to mitigate marble deterioration. Considering that, after 32 months, some cracks in the phosphate layers and some uncoated areas started to appear also in the " $\mathrm{CaCl}_{2}$ " and " $3 \mathrm{M}$ " samples, future tests will be performed to assess the durability of the treatments for longer exposure periods.

- When applied onto a marble sculpture, the consolidating effectiveness of the " $\mathrm{CaCl}_{2}$ " formulation assessed by ultrasounds was lower than in the specimens, as a consequence of the treatment penetration depth. The highest improvements in the sculpture were registered in small carved parts (such as the elephant nose) that were more damaged and where the thickness of the consolidated layer is closer to the thickness of the whole part. The formation of new consolidating phases led to some reduction in water absorption and some color change (which, when visible, consisted in some whitening).

- After field exposure for 25 months, some modest consolidating action was still present in the sculpture, although not very pronounced. Water absorption and color changes were likely influenced by deposition of particulate matter on the marble surface and cleaning before the measurements. Compared to the initial condition, after 25 months all the tested points exhibited minor color changes, in many cases invisible to the human eye and always within the acceptability limit.

All things considered, the present study confirmed the potential of the phosphate treatments, which mitigated marble deterioration during outdoor exposure for 3 years, even though weathering was not completely inhibited. To assess the durability of the phosphate treatments for longer exposure times, the marble specimens and the sculpture will be further monitored in the years to come

Acknowledgements This work has received funding from the European Union's Horizon 2020 research and innovation program under the Marie Skłodowska-Curie grant agreement N. 655239 ("HAP4MARBLE"). Dr. Alexandre Maral (Conservateur général du patrimoine, responsable du département des Sculptures, Musée national des châteaux de Versailles et de Trianon) and Dr. Lionel Arsac (Conservateur du patrimoine, département des Sculptures, Musée national des châteaux de Versailles et de Trianon) are gratefully acknowledged for the opportunity to carry out the field study in the Royal Palace of Versailles. Dr. Claudia Rubino is gratefully acknowledged for collaboration to the characterization tests.

Funding Open access funding provided by Alma Mater Studiorum - Università di Bologna within the CRUI-CARE Agreement.

Open Access This article is licensed under a Creative Commons Attribution 4.0 International License, which permits use, sharing, adaptation, distribution and reproduction in any medium or format, as long as you give appropriate credit to the original author(s) and the source, provide a link to the Creative Commons licence, and indicate if changes were made. The images or other third party material in this article are included in the article's Creative Commons licence, unless indicated otherwise in a credit line to the material. If material is not included in the article's Creative Commons licence and your intended use is not permitted by statutory regulation or exceeds the permitted use, you will need to obtain permission directly from the copyright holder. To view a copy of this licence, visit http://creativecommons.org/licenses/by/4.0/.

\section{References}

1. Sassoni E, Naidu S, Scherer GW (2011) The use of hydroxyapatite as a new inorganic consolidant for damaged carbonate stones. J Cult Herit 12:346-355. https://doi.org/ 10.1016/j.culher.2011.02.005

2. Naidu S, Sassoni E, Scherer GW (2011) New treatment for corrosion-resistant coatings for marble and consolidation of limestone. In: Stefanaggi M, Vergès-Belmin V (eds) Jardins de Pierres-Conservation of Stone in Parks, Gardens and Cemeteries. XL Print, Pairs, France, pp 289-294

3. Sassoni E (2018) Hydroxyapatite and other calcium phosphates for the conservation of cultural heritage: a review. Materials 11:557. https://doi.org/10.3390/ma1 1040557

4. Matteini M, Rescic S, Fratini F, Botticelli G (2011) Ammonium phosphates as consolidating agents for carbonatic stone materials used in architecture and cultural heritage: preliminary research. Int J Archit Herit 5:717-736. https://doi.org/10.1080/15583058.2010.495445

5. Yang F, Zhang B, Liu Y, Wei G, Zhang H, Chen W, Xu Z (2011) Biomimic conservation of weathered calcareous stones by apatite. New J Chem 35:887-892. https://doi.org/ 10.1039/c0nj00783h

6. Sassoni E, Franzoni E (2020) Lime and cement mortar consolidation by ammonium phosphate. Constr Build Mater 245:118409. https://doi.org/10.1016/j.conbuildmat.2020. 118409

7. Masi G, Sassoni E (2020) Comparison between ammonium phosphate and nanolimes for render consolidation. IOP 
Conf Ser Mater Sci Eng 949(1):012039. https://doi.org/10. 1088/1757-899X/949/1/012039

8. Shekofteh A, Molina E, Rueda-Quero L, Arizzi A, Cultrone G (2019) The efficiency of nanolime and dibasic ammonium phosphate in the consolidation of beige limestone from the Pasargadae World Heritage Site. Archaeol AnthroSci 11:5065-5080. https://doi.org/10.1007/s12520-019-00863y

9. Sassoni E, Ugolotti G, Pasgani P (2020) Nanolime, nanosilica or ammonium phosphate? Laboratory and field study on consolidation of a byzantine marble sarcophagus. Constr Build Mater 262:120784. https://doi.org/10.1016/j. conbuildmat.2020.120784

10. Sassoni E, Graziani G, Franzoni E (2016) An innovative phosphate-based consolidant for limestone. Part 1: effectiveness and compatibility in comparison with ethyl silicate. Constr Build Mater 102:918-930. https://doi.org/10.1016/j. conbuildmat.2015.04.026

11. Sassoni E, Graziani G, Franzoni E (2016) An innovative phosphate-based consolidant for limestone. Part 2: durability in comparison with ethyl silicate. Constr Build Mater 102:931-942. https://doi.org/10.1016/j.conbuildmat.2015. 10.202

12. Graziani G, Sassoni E, Franzoni E (2015) Consolidation of porous carbonate stones by an innovative phosphate treatment: mechanical strengthening and physical-microstructural compatibility in comparison with TEOS-based treatments. Heritage Sci 3:1-6. https://doi.org/10.1186/ s40494-014-0031-0

13. Sassoni E, Andreotti S, Scherer GW, Franzoni E, Siegesmund S (2018) Bowing of marble slabs: can the phenomenon be arrested and prevented by inorganic treatments? Environ Earth Sci 77:387. https://doi.org/10. 1007/s12665-018-7547-7

14. Molina E, Fiol C, Cultrone G (2018) Assessment of the efficacy of ethyl silicate and dibasic ammonium phosphate consolidants in improving the durability of two building sandstones from Andalusia (Spain). Environ Earth Sci 77:302. https://doi.org/10.1007/s12665-018-7491-6

15. Sassoni E, Graziani G, Franzoni E (2015) Repair of sugaring marble by ammonium phosphate: comparison with ethyl silicate and ammonium oxalate and pilot application to historic artifact. Mater Des 88:1145-1157. https://doi.org/ 10.1016/j.matdes.2015.09.101

16. Sassoni E, Graziani G, Franzoni E, Scherer GW (2018) Calcium phosphate coatings for marble conservation: influence of ethanol and isopropanol addition to the precipitation medium on the coating microstructure and performance. Corros Sci 136:255-267. https://doi.org/10.1016/ j.corsci.2018.03.019

17. Sassoni E, Graziani G, Franzoni E, Scherer GW (2018) New method for controllable accelerated aging of marble: use for testing of consolidants. J Am Ceram Soc 101:4146-4157. https://doi.org/10.1111/jace.15522

18. Rodriguez-Navarro C, Ruiz-Agudo E (2018) Nanolimes: from synthesis to application. Pure Appl Chem 90:523-550. https://doi.org/10.1515/pac-2017-0506

19. Scherer GW, Wheeler GS (2009) Silicate consolidants for stone. Key Eng Mater 391:1-25. https://doi.org/10.4028/087849-365-4.1
20. Sassoni E, Franzoni E, Pigino B, Scherer GW, Naidu S (2013) Consolidation of calcareous and siliceous sandstones by hydroxyapatite: Comparison with a TEOS-based consolidant. J Cult Herit 14:e103-e108. https://doi.org/10. 1016/j.culher.2012.11.029

21. Naidu S, Scherer GW (2014) Nucleation, growth and evolution of calcium phosphate films on calcite. J Colloid Interface Sci 435:128-137. https://doi.org/10.1016/j.jcis. 2014.08.018

22. Naidu S, Blair J, Scherer GW (2016) Acid-resistant coatings on marble. J Am Ceram Soc 99:3421-3428. https://doi.org/ 10.1111 /jace. 14355

23. Graziani G, Sassoni E, Scherer GW, Franzoni E (2017) Resistance to simulated rain of hydroxyapatite- and calcium oxalate-based coatings for protection of marble against corrosion. Corros Sci 127:168-174. https://doi.org/10.1016/ j.corsci.2017.08.020

24. Weththimuni ML, Licchelli M, Malagodi M, Rovella N, La Russa M (2018) Consolidation of bio-calcarenite stone by treatment based on diammonium hydrogen phosphate and calcium hydroxide nanoparticles. Measurement 127:396-405. https://doi.org/10.1016/j.measurement.2018. 06.007

25. Barriuso BC, Botticelli G, Cuzman OA, Osticioli I, Tiano P, Matteini M (2017) Conservation of calcareous stone monuments: Screening different diammonium phosphate based formulations for countering phototrophic colonization. J Cult Herit 27:97-106. https://doi.org/10.1016/j.culher. 2017.03.002

26. Sassoni E, Franzoni E (2014) Sugaring marble in the Monumental Cemetery in Bologna (Italy): characterization of naturally and artificially weathered samples and first results of consolidation by hydroxyapatite. Appl Phys A 117:1893-1906. https://doi.org/10.1007/s00339-014-86293

27. Molina E, Rueda-Quero L, Benavente D, Burgos-Cara A, Ruiz-Agudo E, Cultrone G (2017) Gypsum crust as a source of calcium for the consolidation of carbonate stones using a calcium phosphate-based consolidant. Constr Build Mater 143:298-311. https://doi.org/10.1016/j.conbuildmat.2017. 03.155

28. Graziani G, Sassoni E, Scherer Franzoni GWE (2018) Phosphate-based treatments for consolidation of salt-bearing Globigerina limestone. IOP Conf Ser Mater Sci Eng 364:012082. https://doi.org/10.1088/1757-899X/364/1/ 012082

29. Praticò Y, Caruso F, Delgado Rodrigues J, Girardet F, Sassoni E, Scherer GW, Vergès-Belmin V, Weiss NR, Wheeler G, Flatt RJ (2019) Stone consolidation: a critical discussion of theoretical insights and field practice. RILEM Tech Lett 4:145-153. https://doi.org/10.21809/ rilemtechlett.2019.101

30. Doherty B, Pamplona M, Miliani C, Matteini M, Sgamellotti A, Brunetti B (2007) Durability of the artificial calcium oxalate protective on two Florentine monuments. J Cult Herit 8:186-192. https://doi.org/10.1016/j.culher.2006.12. 002

31. Charola AE, Centeno SA, Normandin K (2010) The New York Public Library: Protective treatment for sugaring marble. J Archit Conserv 16:29-44. https://doi.org/10.1080/ 13556207.2010.10785068 
32. Dreyfuss T (2019) Interactions on site between powdering porous limestone, natural salt mixtures and applied ammonium oxalate. Herit Sci 7:5. https://doi.org/10.1186/s40494019-0247-0

33. Michette M, Viles H, Vlachou-Mogire C, Angus I (2020) Assessing the long-term success of reigate stone conservation at hampton court palace and the tower of London. Stud Conserv. https://doi.org/10.1080/00393630.2020.1752427

34. Sandrolini F, Franzoni E, Sassoni E, Diotallevi PP (2011) The contribution of urban-scale environmental monitoring to materials diagnostics: a study on the Cathedral of Modena (Italy). J Cult Herit 12:441-450. https://doi.org/10.1016/j. culher.2011.04.005

35. Natali I, Tomasin P, Becherini F, Bernardi A, Ciantelli C, Favaro M, Favoni O, Forrat Pérez VJ, Olteanu ID, Romero Sanchez MD, Vivarelli A, Bonazza A (2015) Innovative consolidating products for stone materials: field exposure tests as a valid approach for assessing durability. Herit Sci 3:6. https://doi.org/10.1186/s40494-015-0036-3

36. Ma X, Balonis M, Pasco H, Toumazou M, Counts D, Kakoulli I (2017) Evaluation of hydroxyapatite effects for the consolidation of a Hellenistic-Roman rock-cut chamber tomb at Athienou-Malloura in Cyprus. Constr Build Mater 150:333-344. https://doi.org/10.1016/j.conbuildmat.2017. 06.012

37. Scherer GW, Franzoni E, Sassoni E, Graziani G (2018) Phosphate consolidants for carbonate stones. APT Bull J Preserv Technol 49:61-68

38. Graziani G, Sassoni E, Franzoni E, Scherer GW (2016) Hydroxyapatite coatings for marble protection: optimization of calcite covering and acid resistance. Appl Surf Sci 368:241-257. https://doi.org/10.1016/j.apsusc.2016.01.202

39. Franzoni E, Sassoni E, Graziani G (2015) Brushing, poultice or immersion? The role of the application technique on the performance of a novel hydroxyapatite-based consolidating treatment for limestone. J Cult Herit 16:173-184. https:// doi.org/10.1016/j.culher.2014.05.009

40. Scherer GW, Sassoni E (2016) Mineral Consolidants. In: Proceedings of the International RILEM Conference Materials, Systems and Structures in Civil Engineering 2016-Segment on Historical Masonry; Rörig-Dalgaard, I., Ioannou, I., Eds.; Technical University of Denmark: Lyngby, Denmark; pp. 1-10

41. Matteini M (2008) Inorganic treatments for the consolidation and protection of stone artefacts. Conserv Sci Cult Herit 8:13-27

42. Ruedrich J, Knell C, Enseleit J, Rieffel Y (2013) Siegesmund, S. Stability assessment of marble statuaries of the Schlossbrucke (Berlin, Germany) based on rock strength measurements and ultrasonic wave velocities. Environ Earth Sci 69:1451-1469. https://doi.org/10.1007/s12665013-2246-x

43. Vandevoorde D, Pamplona M, Schalm O, Vanhellemont Y, Cnudde V, Verhaeven E (2009) Contact sponge method: Performance of a promising tool for measuring the initial water absorption. J Cult Herit 10:41-47. https://doi.org/10. 1016/j.culher.2008.10.002

44. Franzen C (2018) Sheltering of stone art. Environ Earth Sci 77:299. https://doi.org/10.1007/s12665-018-7478-3
45. Köhler W (1988) Preservation problems of Carrara marble sculptures: Potsdam-Sanssouci ("radical structural destruction" of Carrara marble). VI International Congress on Deterioration and Conservation of Stone, Proc Actes, 653-662

46. Conti C, Casati M, Colombo C, Possenti E, Realini M, Gatta D, Merlini M, Brambilla L, Zerbi G (2015) Synthesis of calcium oxalate trihydrate: New data by vibrational spectroscopy and synchrotron X-ray diffraction. Spectrochim Acta A Mol Biomol 150:721-730. https://doi.org/10.1016/j. saa.2015.06.009

47. Naidu S, Liu C, Scherer GW (2015) Hydroxyapatite-based consolidant and the acceleration of hydrolysis of silicatebased consolidants. J Cult Herit 16:94-101. https://doi.org/ 10.1016/j.culher.2014.01.001

48. Tao J (2013) FTIR and raman studies of structure and bonding in mineral and organic-mineral composites. Methods Enzymol 532:533-556. https://doi.org/10.1016/ B978-0-12-416617-2.00022-9

49. Karampas IA, Kontoyannis CG (2013) Characterization of calcium phosphates mixtures. Vib Spectrosc 64:26-133. https://doi.org/10.1016/j.vibspec.2012.11.003

50. Sharma G (2003) Color fundamentals for digital imaging. Digital color imagining handbook. CRC Press, Boca Raton, FL, USA

51. Delgado Rodrigues J, Grossi A (2007) Indicators and ratings for the compatibility assessment of conservation actions. J Cult Herit 8:32-43. https://doi.org/10.1016/j.culher.2006. 04.007

52. Siegesmund S, Ullemeyer K, Weiss T, Tschegg EK (2000) Physical weathering of marbles caused by anisotropic thermal expansion. Int J Earth Sci 89:170-182. https://doi. org/10.1007/s005310050324

53. Luque A, Ruiz-Agudo E, Cultrone G, Sebastiàn E, Siegesmund S (2011) Direct observation of microcrack development in marble caused by thermal weathering. Environ Earth Sci 62:1375-1386. https://doi.org/10.1007/s12665010-0624-1

54. Sassoni E, Franzoni E (2014) Influence of porosity on artificial deterioration of marble and limestone by heating. Appl Phys A 115:809-816. https://doi.org/10.1007/s00339013-7863-4

55. Ruedrich J, Weiss T, Siegesmund S (2002) Thermal behavior of weathered and consolidated marbles. In: Siegesmund S, Weiss T, Vollbrecht A (eds) Natural stone, weathering phenomena, conservation strategies and case studies, Geological Society. Special Publications, London

56. Menningen J, Siegesmund S, Krompholz R, Rieffel Y (2020) The marble sculptures of General Bülow and Scharnhorst in Berlin: comparative, non-destructive analysis of the weathering state after 12 years of exposure. Environ Earth Sci 79:249. https://doi.org/10.1007/s12665020-08984-7

Publisher's Note Springer Nature remains neutral with regard to jurisdictional claims in published maps and institutional affiliations. 